This is the author's manuscript for publication. The publisher-formatted version may be available through the publisher's web site or your institution's library.

\title{
Crop supply dynamics and the illusion of partial adjustment
}

Nathan P. Hendricks, Aaron Smith, and Daniel A. Sumner

\section{How to cite this manuscript}

If you make reference to this version of the manuscript, use the following information:

Hendricks, N. P., Smith, A., \& Sumner, D. A. (2014). Crop supply dynamics and the illusion of partial adjustment. Retrieved from http://krex.ksu.edu

\section{Published Version Information}

Citation: Hendricks, N. P., Smith, A., \& Sumner, D. A. (2014). Crop supply dynamics and the illusion of partial adjustment. American Journal of Agricultural Economics, 96(5), 1469-1491.

Copyright: ( The Author (2014). Published by Oxford University Press on behalf of the Agricultural and Applied Economics Association.

Digital Object Identifier (DOI): doi:10.1093/ajae/aau024

Publisher's Link: http://ajae.oxfordjournals.org/content/96/5/1469.full

This item was retrieved from the K-State Research Exchange (K-REx), the institutional repository of Kansas State University. K-REx is available at http://krex.ksu.edu 


\title{
Crop Supply Dynamics and the Illusion of Partial Adjustment
}

\author{
Nathan P. Hendricks, Aaron Smith, and Daniel A. Sumner
}

February 2014

\begin{abstract}
We use field-level data to estimate the response of corn and soybean acreage to price shocks. Our sample contains more than eight million observations derived from satellite imagery and includes every field in Iowa, Illinois, and Indiana. We estimate that aggregate crop acreage responds more to price shocks in the short run than in the long run, and we show theoretically how the benefits of crop rotation generate this response pattern. In essence, farmers who change crops due to a price shock have an incentive to switch back to the previous crop to capture the benefits of crop rotation. Our result contradicts the long-held belief that agricultural supply responds gradually to price shocks through partial adjustment. We would not have obtained this result had we used county-level panel data. Standard econometric methods applied to county-level data produce estimates consistent with partial adjustment. We show that this apparent partial adjustment is illusory, and we demonstrate how it arises from the fact that fields in the same county are more similar to each other than to fields in other counties. This result underscores the importance of using models with appropriate micro-foundations and cautions against inferring micro-level rigidities from inertia in aggregate panel data. Our preferred estimate of the own-price long-run elasticity of corn acreage is 0.29 and the cross-price elasticity is -0.22 . The corresponding elasticities for soybean acreage are 0.26 and -0.33 . Our estimated short-run elasticities are 37 percent larger than their long-run counterparts.
\end{abstract}

Keywords: Aggregation, Crop Rotation, Dynamic Panel Econometrics

JEL codes: Q11

Running head: Crop Supply Dynamics

Nathan P. Hendricks is an assistant professor in the Department of Agricultural Economics at Kansas State University. Aaron Smith is a professor in the Department of Agricultural and Resource Economics at the University of California, Davis and a member of the Giannini Foundation of Agricultural Economics. Daniel A. Sumner is the Frank H. Buck, Jr., Professor in the Department of Agricultural and Resource Economics at the University of California, Davis, the director of the University of California, Agricultural Issues Center, and a member of the Giannini Foundation of Agricultural Economics. The authors thank the editor, anonymous reviewers, and seminar participants at the University of Illinois for helpful comments. This material is based upon work supported by the United States Department of 
Agriculture under Agreement No. 58-0111-10-005 and by the National Science Foundation under Award No. EPS-0903806 and matching support from the State of Kansas through the Kansas Board of Regents. 
How much more land gets allocated to a crop when relative prices change? The answer to this question is the central parameter for understanding world food prospects, the impacts of farm subsidies, and the environmental consequences from land use change, among other public and policy issues (e.g., Roberts and Schlenker 2013; Lichtenberg and Zilberman 1986; Searchinger et al. 2008; Donner and Kucharik 2008). We provide a new and better answer for an important set of commodities in the world food system. We use a conceptual approach that accounts for crop rotations, a massive sample of individual fields, and econometric methods that account for heterogeneous incentives to rotate crops and heterogeneous responses to prices. Moreover, we show that supply response is seriously misestimated when standard econometric methods are applied to county-level panel data. One consequence of this bias is a mistaken understanding of supply dynamics and, in particular, the relationship between short-run and long-run supply response.

A typical agricultural field in the United States Corn Belt tends to alternate between growing corn in one year and soybeans the next. This pattern reflects a common agronomic feature of crop production: planting a crop on the same field in consecutive years decreases the productivity of the soil for growing that crop and increases pest populations. These features generate dynamic complementarity in crop production because the marginal value of planting a particular crop this year depends on what was planted on that field the previous year. In this article, we show theoretically and empirically that these field-level dynamics imply that aggregate acreage of a crop responds to price shocks more in the short run than in the long run (5-10 years). ${ }^{1}$ For corn and soybeans, we estimate that the short-run elasticity of planted-acreage with respect to price exceeds its long-run counterpart by 37 percent.

Intuitively, the short-run response exceeds the long-run response in the Corn Belt because farmers who change crops due to a price shock have an incentive to switch back to the previous crop to capture the benefits of crop rotation. For example, if the price of corn increases permanently, some land previously planted to continuous soybeans would switch to a corn-soybean rotation and would plant corn first, then rotate to soybeans in the second 
year. Thus, aggregate corn acreage would decrease in the second year, even if prices were to stay constant.

Our results stand in contrast to the existing literature which, since the seminal work of Nerlove (1958), has held that farmers respond gradually to price shocks over time. The partial-adjustment hypothesis has been reinforced by numerous empirical studies that estimate the short-run response is much smaller than the long-run response to price for crops. A typical such study estimates a regression model containing a lagged dependent variable and interprets a positive coefficient on the lag as a measure of the extent of partial adjustment. Askari and Cummings (1977) provide an early review of this literature, and a recent example is de Menezes and Piketty (2012).

We recognize that there are several important settings where adjustment requires substantial changes in physical and human capital and agricultural supply is likely to respond less to price shocks in the short run than in the long run. For example, response to price shocks in the long run may exceed response in the short run for perennial crops or when supply response involves the conversion of grasslands or wetlands. However, our results call into question standard methods used to quantify this adjustment process with aggregate panel data and overturn the conventional wisdom for an important set of commodities.

Unlike prior studies of crop supply response, we use a novel set of field-level crop data derived from satellite imagery that includes every field in Iowa (2000-2010), Illinois (19992010), and Indiana (2000-2010). Our sample accounts for roughly 15 percent of world corn and soybean production. To generate our estimated supply elasticities, we estimate firstorder Markov transition probabilities. ${ }^{2}$ We separately estimate price responses along the rotational margin (transitions between corn and soybeans) and the extensive margin (transitions between corn or soybeans and other crops). Although we have more than 8 million observations, we only have roughly 11 years of data. In order to account for spatial dependence in the data, we cluster standard errors by year. In dynamic panel regression models of the type that we estimate, coefficient heterogeneity can induce potentially large 
biases (Robertson and Symons 1992; Pesaran and Smith 1995). We alleviate such biases by estimating separate econometric models for 24 regions with different soil and climate characteristics.

To show the value of using field-level data, we also estimate crop supply response by applying standard dynamic panel estimators to county-level data. This exercise produces a short-run response to price that is roughly 20 percent smaller than the long-run response. This finding contradicts our result with field-level data that the short-run response is 37 percent larger than the long-run response. We show that the illusion of partial adjustment in county-level data arises because aggregating over similar micro units (i.e., fields in the same county) inflates the bias due to coefficients that differ across fields (Robertson and Symons 1992; Pesaran and Smith 1995). Our results indicate that researchers should exercise caution in interpreting dynamic economic behavior from commonly used dynamic panel estimators, especially if the panels represent aggregates over similar micro units.

The illusion of partial adjustment stems not from aggregation per se, but from the fact that county-level data represent aggregates across similar fields. To illustrate this point with our data, we create pseudo-county data by randomly assigning fields to groups and aggregating within each group. Using this group-level data, we re-estimate our models and obtain similar estimates to those we obtain with our field-level data. This result arises because most of the heterogeneity is averaged out in the aggregation of groups that are randomly assigned. Similarly, aggregating to a national time series (if we had a long enough time series) might also mitigate the biases that arise in the county-level panel. ${ }^{3}$

\section{Conceptual Model of Aggregate Acreage Response to Price}

We develop a stylized model of the aggregate long-run and short-run acreage response to price that incorporates heterogeneous incentives to rotate crops. To simplify the model, we consider the two commodities corn and soybeans. If the farmer rotates the crops, then fewer inputs are required to obtain a given yield and a greater yield is obtained for a given level of 
inputs. To focus on the implications for supply response, we simplify the model by assuming a zero discount rate, risk neutrality, and no economies of scope or scale. ${ }^{4}$ We assume that only the crop from the previous year affects the production of the current crop (i.e., one-year memory of the rotation). In the supplementary online appendix, we extend the results to the case of two-year memory.

First, assume that prices are known with certainty and constant over time. ${ }^{5}$ The farmer chooses a rotation of corn and soybeans that maximizes profits over the length of the rotation. Hennessy (2006) shows that under one-year memory the set of optimal crop rotations is restricted to continuous corn, continuous soybeans, or corn-soybeans denoted as $\langle c c\rangle,\langle s s\rangle$, and $\langle c s\rangle .{ }^{6}$ Intuitively, if $\langle c s\rangle$ dominates $\langle c c\rangle$, then $\langle c s\rangle$ must also dominate $\langle c c s\rangle$ under one-year memory. Similarly, if $\langle c c\rangle$ dominates $\langle c s\rangle$, then $\langle c c\rangle$ must also dominate $\langle c c s\rangle$.

Let $c_{i t}$ denote a binary variable that equals one if corn is planted and zero if soybeans are planted on field $i$ in year $t$. We denote the quantity of input applied to corn as $x_{i t}^{c}$ and to soybeans as $x_{i t}^{s}$. For simplicity, we assume that a single input, such as fertilizer, is used in production. The farmer obtains profit $\pi_{i t}^{c}$ if corn is planted and $\pi_{i t}^{s}$ if soybeans are planted in year $t$. The farmer maximizes the profits over the length of the longest rotation in the set of all possible optimal rotations,

(1) $\max _{\mathbf{c}_{i}, \mathbf{x}_{i}} \sum_{t=1}^{2}\left[c_{i t} \pi_{i t}^{c}\left(x_{i t}^{c}, c_{i, t-1}\right)+\left(1-c_{i t}\right) \pi_{i t}^{s}\left(x_{i t}^{s}, c_{i, t-1}\right)\right]$,

where the rotations continually repeat $(t=0 \Rightarrow t=2)$. The farmer maximizes profits by choosing the crop to plant in both periods (denoted $\mathbf{c}_{i}$ ) and the inputs to apply to each crop in both periods (denoted $\mathbf{x}_{i}$ ).

We write the period- $t$ profit from corn and soybeans as

$$
\begin{aligned}
& \pi_{i t}^{c}\left(x_{i t}^{c}, c_{i, t-1}\right)=p_{i}^{c}\left[y_{i}^{c}\left(x_{i t}^{c}+\left(1-c_{i, t-1}\right) N_{i}^{s c}\right)+\left(1-c_{i, t-1}\right) B_{i}^{s c}\right]-w_{i} x_{i t}^{c}, \\
& \pi_{i t}^{s}\left(x_{i t}^{s}, c_{i, t-1}\right)=p_{i}^{s}\left[y_{i}^{s}\left(x_{i t}^{s}+c_{i, t-1} N_{i}^{c s}\right)+c_{i, t-1} B_{i}^{c s}\right]-w_{i} x_{i t}^{s},
\end{aligned}
$$


where $p_{i}^{j}$ is the price of crop $j$ that includes per unit government payments, $y_{i}^{j}(\cdot)$ is the yield function that is assumed constant over time, ${ }^{7}$ and $w_{i}$ is the price of the input. If corn is planted after soybeans, then the equivalent of $N_{i}^{s c}$ units of input are applied to corn (i.e., $N_{i}^{s c}$ is a perfect substitute for $x_{i t}^{c}$ ). For example, if corn is planted after soybeans, then nitrogen carries over from the soybeans and weed and insect pressures are reduced - providing a substitute for chemical fertilizers, herbicides, and insecticides. Similarly, if soybeans are planted after corn, then the equivalent of $N_{i}^{c s}$ units of input are applied to soybeans. In addition, corn production receives a yield boost of $B_{i}^{s c}$ if soybeans were planted the previous year and soybean production receives a yield boost of $B_{i}^{c s}$ if corn was planted the previous year. The profit functions in equations (2) and (3) assume that the reduction in inputs and the yield boost from rotating crops enter the production function additively as in Hennessy $(2006){ }^{8}$

The optimal crop rotation is given by the following set of conditions (Hennessy 2006):

$$
\begin{gathered}
\langle c c\rangle \text { if } \quad \tilde{\pi}_{i}^{c c}-\tilde{\pi}_{i}^{s s} \geq p_{i}^{c} B_{i}^{s c}+p_{i}^{s} B_{i}^{c s}+w_{i}\left(N_{i}^{s c}+N_{i}^{c s}\right), \\
\langle s s\rangle \text { if } \quad \tilde{\pi}_{i}^{s s}-\tilde{\pi}_{i}^{c c} \geq p_{i}^{c} B_{i}^{s c}+p_{i}^{s} B_{i}^{c s}+w_{i}\left(N_{i}^{s c}+N_{i}^{c s}\right), \\
\langle c s\rangle \text { if }\left|\tilde{\pi}_{i}^{c c}-\tilde{\pi}_{i}^{s s}\right| \leq p_{i}^{c} B_{i}^{s c}+p_{i}^{s} B_{i}^{c s}+w_{i}\left(N_{i}^{s c}+N_{i}^{c s}\right),
\end{gathered}
$$

where $\tilde{\pi}_{i}^{c c}$ and $\tilde{\pi}_{i}^{s s}$ denote the indirect profit functions of growing corn after corn and soybeans after soybeans. ${ }^{9}$

Now consider the effect on planting decisions of an immediate unanticipated permanent change in output prices. Assuming constant prices in future crop years, the optimal rotation in the current year is either $\langle c c\rangle,\langle s s\rangle$, or $\langle c s\rangle$. The farmer will determine the optimal rotation at current prices and begin that rotation immediately, regardless of the previous crop. Even though the optimal rotation does not depend on the previous crop, the optimal crop decision does depend on the previous crop. If corn was planted the previous year, then corn is optimal in the current year only if the optimal rotation is $\langle c c\rangle$ at current-and 
future-prices. However, if soybeans were planted the previous year, then corn is optimal in the current year if the optimal rotation is $\langle c c\rangle$ or $\langle c s\rangle$ at current prices - or conversely, if the optimal rotation is not $\langle s s\rangle$. If the farmer planted corn in the previous year $\left(c_{i, t-1}=1\right)$, then she chooses to plant corn this year if

$$
\tilde{\pi}_{i t}^{c c}-\tilde{\pi}_{i t}^{s s} \geq p_{i t}^{c} B_{i}^{s c}+p_{i t}^{s} B_{i}^{c s}+w_{i t}\left(N_{i}^{s c}+N_{i}^{c s}\right) .
$$

However, if she planted soybeans in the previous year $\left(c_{i, t-1}=0\right)$, then she chooses to plant corn this year if

$$
\tilde{\pi}_{i t}^{c c}-\tilde{\pi}_{i t}^{s s} \geq-\left(p_{i t}^{c} B_{i}^{s c}+p_{i t}^{s} B_{i}^{c s}+w_{i t}\left(N_{i}^{s c}+N_{i}^{c s}\right)\right) .
$$

Conditions (7) and (8) provide the theoretical basis for specifying our econometric model. Next, we aggregate these field-level cropping decisions across heterogeneous fields to characterize the dynamics of the aggregate acreage response to price.

To simplify aggregation, assume that there is a single parameter, $\theta$, that represents the land type, and $\theta$ has a probability density function $g(\theta)$ and cumulative distribution function $G(\theta)$ (see Lichtenberg 2002). The parameter $\theta$ represents a whole range of ways that fields may differ including soils and climate. Let $\theta$ be scaled such that for a given set of prices it is optimal for fields with $\theta \leq \theta^{L}$ to plant continuous corn, with $\theta^{L}<\theta \leq \theta^{H}$ to plant corn-soybeans, with $\theta^{H}<\theta \leq \theta^{*}$ to plant continuous soybeans, and with $\theta^{*}<\theta$ to plant a crop other than corn or soybeans. This set of assumptions is illustrated in figure $1 .{ }^{10}$

Denote the aggregate share of all acres planted to corn as $\bar{C}$. If all fields are in a steadystate, long-run equilibrium, then all of the continuous corn acres are planted to corn, half of the corn-soybean acres are planted to corn, and none of the continuous soybean acres are planted to corn. The long-run aggregate share of corn acres can be written as

$$
\bar{C}^{L R}=1 \cdot G\left(\theta^{L}\right)+\frac{1}{2} \cdot\left(G\left(\theta^{H}\right)-G\left(\theta^{L}\right)\right)+0 \cdot\left(G\left(\theta^{*}\right)-G\left(\theta^{H}\right)\right) .
$$


Let $p=p^{c} / p^{s}$ denote the relative price of corn to soybeans. The differential of the long-run share of corn acres is

$$
d \bar{C}^{L R}=\frac{1}{2}\left(g\left(\theta^{L}\right) \frac{\partial \theta^{L}}{\partial p} d p+g\left(\theta^{H}\right) \frac{\partial \theta^{H}}{\partial p} d p\right)
$$

We assume that continuous corn acres are increasing and continuous soybean acres are decreasing with respect to the relative price of corn to soybeans (i.e., $\frac{\partial \theta^{L}}{\partial p}>0$ and $\frac{\partial \theta^{H}}{\partial p}>0$ ).

Now consider the change in the share of corn acres in the the short run from an increase in the relative price of corn (i.e., the change in the first year following a price shock) assuming that in the initial period acres are in long-run equilibrium. The change in price causes some land to switch from corn-soybeans to continuous corn and some land to switch from continuous soybeans to corn-soybeans. All of the fields that switch from corn-soybeans to continuous corn plant corn in the short run, so $1 / 2$ of these fields plant corn that otherwise would have planted soybeans in the absence of a price shock. All of the fields that switch from continuous soybeans to corn-soybeans plant corn in the short run, so all of these fields plant corn that otherwise would have planted soybeans. Written in differential form, the short-run change in the share of acres planted to corn is

$$
d \bar{C}^{S R}=\frac{1}{2} g\left(\theta^{L}\right) \frac{\partial \theta^{L}}{\partial p} d p+g\left(\theta^{H}\right) \frac{\partial \theta^{H}}{\partial p} d p \quad \text { if } d p>0 .
$$

Using similar reasoning, the short-run response to a decrease in the relative price is

$$
d \bar{C}^{S R}=g\left(\theta^{L}\right) \frac{\partial \theta^{L}}{\partial p} d p+\frac{1}{2} g\left(\theta^{H}\right) \frac{\partial \theta^{H}}{\partial p} d p \quad \text { if } d p<0 .
$$


Subtracting the long-run response in (10) from the short-run responses in (11) and (12) gives

$$
d \bar{C}^{S R}-d \bar{C}^{L R}= \begin{cases}\frac{1}{2} g\left(\theta^{H}\right) \frac{\partial \theta^{H}}{\partial p} d p & \text { if } d p>0 \\ \frac{1}{2} g\left(\theta^{L}\right) \frac{\partial \theta^{L}}{\partial p} d p & \text { if } d p<0\end{cases}
$$

Thus, the short-run response to price is larger than the long-run response. The difference between the short-run and long-run response occurs due to the conversion from continuous cropping to a crop rotation. When the relative price increases, all of the fields that switch from continuous soybeans to corn-soybeans are planted to corn in the short run, but in the long run only half of these fields are planted to corn. Our model also implies that price shocks cause acreage to oscillate around the long-run equilibrium, so even a temporary price shock causes oscillations in future acreage. In the supplementary online appendix, we show that in the case of two-year memory the conceptual model still implies that the short-run response to price is larger than the long-run response. ${ }^{11}$

If there is uncertainty about prices in future years, then the farmer accounts for an option value of changing crops in the future if prices are different than expected. For example, even though it may be more profitable to plant corn in the current year, a fully rational farmer may plant soybeans because of the possibility that higher than expected corn prices next year could yield even higher profits. Planting corn this year would preclude taking advantage of that opportunity because of the yield drag. While our stylized model ignores this option value, it allows us to conceptually characterize the dynamics of supply response without substantial complications. Livingston, Roberts, and Zhang (2013) formulate a stochasticdynamic programming model of rotating corn and soybeans that incorporates rational price expectations, but must solve the model numerically.

The features of acreage response to price from our model are similar to those described in Eckstein (1984), who developed a land allocation model where the current productivity of one crop increases if the land allocated to the other crop was larger in the previous year. 
However, there has been little empirical support in the literature for the hypothesis that the short-run response to price is larger than the long-run response when crops are rotated. Even Eckstein (1984) estimated that the short-run response was smaller than the long-run response in an application to aggregate crop data from Egypt. The only exception we found is Tegene, Huffman, and Miranowski (1988), who estimate a model of corn acreage in Iowa using aggregate time-series data for the period 1948-1980 and find that the short-run acreage elasticity is 0.236 and the long-run elasticity is 0.220 . In contrast, we estimate that the shortrun response is substantially larger than the long-run response. We also show that estimates of the dynamics of supply are severely biased when using aggregate panel data.

\section{Data}

Next, we describe our methods in constructing the data for the empirical analysis. Descriptive statistics of our data are shown in table 1.

\section{Crop Data and Field Boundaries}

Our crop data come from the Cropland Data Layer (CDL) ${ }^{12}$ which is produced by the National Agricultural Statistics Service (NASS) of the United States Department of Agriculture (USDA). NASS describes the CDL as a "census by satellite." The CDL is an image of an

entire state with a crop or land use classification code corresponding to each pixel, where each pixel is less than one acre in size. NASS classifies pixels using data from satellite sensors and performs validation exercises to "ground truth" the data. We use Common Land Unit boundaries in 2007 from the Farm Service Agency to approximate "field" boundaries. We choose a point near the centroid of the Common Land Unit as our unit of analysis. ${ }^{13}$ Figure 2 gives an example of two areas with Cropland Data Layer classifications overlayed with Common Land Unit boundaries and the points that we select from each of these Common Land Units to form our panel of "field-level" crop data (a color figure is available in the on- 
line version of this article). Our analysis uses crop data in Illinois for the period 1999-2010 and Iowa and Indiana for 2000-2010.

Our empirical analysis uses three crop classifications: corn, soybeans, and other crops (primarily alfalfa and wheat). According to accuracy assessments conducted by NASS, the probability that the CDL correctly classifies corn or soybeans is roughly $95 \%$ on average in these three states. The CDL is less accurate at distinguishing between other crops, so we merge them all into a single category. Our econometric model does not estimate changes in corn and soybean acres from transitions with noncrop land uses partly because the CDL is less accurate at classifying noncrop land uses and because noncrop land use, say for grazing livestock, is a small part of the land mix that is ever planted to crops in the central Corn Belt. In the supplementary online appendix, we use aggregate data on noncrop acreage to show that changes in corn and soybean acres due to transitions with noncrop land uses are likely to be negligible for these three states.

\section{Expected Crop Prices}

In our econometric model, the right-hand side regressor is the expected effective price prior to planting including per-unit government payments - for which we use the shorthand "expected price." Expected crop prices are the sum of a futures price, an expected basis ${ }^{14}$, and an expected loan deficiency payment. For corn, the futures price is the average price in JanuaryMarch of a December futures contract. For soybeans, the futures price is the average price in January-March of a November futures contract. Futures price data are obtained from the Commodity Research Bureau.

We use the basis in March, prior to planting, as the expectation for the harvest basis. The basis in March provides a reasonable expected basis prior to planting because storage bounds

temporal-arbitrage opportunities. To measure the basis, we use spot prices in March for 93 market locations in the three states for corn and 90 locations for soybeans from GeoGrain. We then interpolate to every point in the crop dataset using inverse distance weighting. 
The U.S. government provides a subsidy for corn and soybeans when market prices are low - called loan deficiency payments - and had such a program throughout the data period. The loan deficiency payment equals the difference between a county-specific loan rate and the posted county price - the government's measure of the local market price - times the farmer's production, but is only triggered when the posted county price falls below the county-specific loan rate. This program provides a payment to growers but does not create a floor price for buyers and the government acquires no commodities, so we assume the loan rate truncates the price distribution from below. We use the formula for a truncated mean to estimate an expected price that incorporates the possibility of a loan deficiency payment assuming that the harvest-price distribution has a lognormal conditional distribution where the standard deviation is the implied volatility of options contracts. We assume the expected loan deficiency payment is constant across counties and varies only by year. Implied volatility data are from the Commodity Research Bureau. Loan rate and posted county price data are from the Farm Service Agency. Further details about constructing expected prices are available in the supplementary online appendix.

We construct a Laspeyres index of expected corn and soybean prices and a Laspeyres index of expected alfalfa and wheat prices for the analysis of changes between corn and soybeans and other crops. We construct these indices at the county level using the expected crop yield times the crop acreage in 2000 as the weights for expected prices. Expected yield is the prediction from county-specific regressions with a linear trend using NASS county-level data from 1980 to 2010. The expected alfalfa price, for which no futures market exists, is the average January-March price in Iowa. ${ }^{15}$ The expected wheat price is the sum of a futures price and an expected loan deficiency payment.

\section{Other Data}

We collected data on soil texture (percent clay, percent silt, and percent sand) and slope from the Soil Survey Geographic (SSURGO) database from NRCS. County-level data on the 
share of cropland that is irrigated are from the 2007 Census of Agriculture. We obtained precipitation in April and May for each year from PRISM (Parameter-elevation Regressions on Independent Slopes Model). PRISM interpolates precipitation data to create a grid of monthly precipitation with a resolution of about 2.5 miles x 2.5 miles. Corn is typically planted earlier than soybeans, but heavy rainfall can sometimes prevent corn from being planted on time and thereby prompt substitution to another crop. To capture this possibility, we include a dummy variable in our regressions that indicates if April-May precipitation was greater than the 75 th percentile in the three states during our sample period.

\section{Suggestive Evidence Supporting the Conceptual Model}

Figure 3 shows aggregate data on relative prices, crop acreage, and crop transitions for Iowa, Illinois, and Indiana during our sample period. Although the large increase in food commodity prices - often referred to as the "food price crisis" - occurred in 2008, figure 3a shows that a large shock in the relative expected price for corn to soybeans occurred in 2007 as corn prices increased before soybean prices.

The shock in relative expected prices was accompanied by a sharp increase in corn acreage in 2007 that was almost completely offset by a decrease in soybean acreage (figure $3 \mathrm{~b}$ ). In 2008, corn acreage decreased sharply and this was offset by an increase in soybean acreage. The decrease in corn acreage in 2008, after the price shock in 2007, supports the hypothesis that the response to a price shock is larger in the short run than in the long run, although this evidence is only suggestive because it relies on one observation and the relative price of corn also decreased in 2008.

We find stronger evidence to support the claim that the price response is larger in the short run than the long run by examining crop transitions from our field-level data (see figure 3c). The shock in relative prices in 2007 was accompanied by a decrease in soybeans after soybeans and an increase in corn after soybeans, as well as a decrease in soybeans after corn and an increase in corn after corn. ${ }^{16}$ The crop transitions were out of steady-state in 
2007 (corn after soybean transitions were not equal to soybean after corn transitions). So in 2008, corn after soybean transitions decreased and soybean after corn transitions increased, leading to a decrease in corn acres. Thus, the data on crop transitions provides evidence to support our hypothesis of supply dynamics as can be seen from the oscillation in corn after soybeans and soybeans after corn following a price shock. Next, we provide a more formal evaluation by estimating an econometric model.

\section{Econometric Model}

The preceding discussion emphasizes transitions between corn and soybeans, which fits our empirical setting well. Our estimation sample contains roughly 8.75 million observations, each one representing a crop planted in a particular field in a particular year. Of these observations, 98 percent are planted to either corn or soybeans; the other two percent are planted to other crops such as wheat or alfalfa. ${ }^{17}$ In our econometric analysis, we separately estimate price responses along the "rotational margin" (transitions between corn and soybeans) and the "extensive margin" (transitions between corn or soybeans and other crops), and then add them together to obtain total elasticities. This model setup implies that farmers make sequential decisions, first deciding whether to plant one of the two main crops (corn and soybeans) or another crop and then deciding which crop to plant. ${ }^{18}$

Our conceptual model indicates that the planting decision at the rotational margin depends on the previous crop (see equations (7) and (8)). We set up a first-order Markov model with two states. Denote corn as state 1 and soybeans as state 2 . We specify the following model for the transitions between the two states:

$$
\begin{aligned}
& \Phi_{i t}^{11}=\operatorname{Pr}\left(c_{i t}=1 \mid c_{i, t-1}=1\right)=\lambda_{1 i}+\beta_{1 i}^{c} p_{i t}^{c}+\beta_{1 i}^{s} p_{i t}^{s}+\boldsymbol{\theta}_{1 i}^{\prime} \mathbf{x}_{i}+\kappa_{1 i} t \\
& \Phi_{i t}^{21}=\operatorname{Pr}\left(c_{i t}=1 \mid c_{i, t-1}=0\right)=\lambda_{2 i}+\beta_{2 i}^{c} p_{i t}^{c}+\beta_{2 i}^{s} p_{i t}^{s}+\boldsymbol{\theta}_{2 i}^{\prime} \mathbf{x}_{i}+\kappa_{2 i} t
\end{aligned}
$$


where $\Phi_{i t}^{m j}$ denotes the probability of a transition from state $m$ to state $j$ on field $i$ in year $t, p_{i t}^{c}$ is the expected effective price of corn including government payments, $p_{i t}^{s}$ is the expected effective price of soybeans including government payments, $\mathbf{x}_{i}$ is a vector of field characteristics (an indicator of large spring rainfall, share clay, share silt, slope, and share of county irrigated), and $t$ is a time trend. These two equations are sufficient to describe the system because $\Phi_{i t}^{12}=1-\Phi_{i t}^{11}, \Phi_{i t}^{22}=1-\Phi_{i t}^{21}$. We write each coefficient with an $i$ subscript to allow heterogeneity across fields.

We assume that expected price is exogenous. Hendricks, Janzen, and Smith (2013) find small differences between OLS estimates and IV estimates in regressions of aggregate acreage on price. They suggest that yield deviations from trend may serve as a proxy to control for anticipated supply shocks, but yield deviations from trend are likely endogenous in our study since changes in crop rotation affect yields. We omit input prices from our econometric model. We recognize that prices for inputs that differ in their intensity of use between corn and soybean production - most notably fertilizer-may affect decisions at the rotational margin. However, in the supplementary online appendix, we use University of Illinois crop budgets to show that changes in the price of fertilizer make a much smaller difference in the relative returns of crop rotations than changes in crop prices. We also show in the online appendix that our acreage elasticities are robust to controlling for the price of fertilizer in our regressions. Our preferred specification omits the price of fertilizer because we recognize the limitations of identifying the effect of the price of fertilizer separately from crop prices with only 11 years of data.

We can specify the econometric model with Markov transition probabilities that depend on expected prices only in the current crop year by assuming the expected price in the current year embodies all of the price information relevant for decisions in future crop years. Incorporating forward-looking price expectations into the econometric model would require a dynamic discrete choice model á la Rust (1987). A dynamic discrete choice model would substantially increase the computational burden and require a different set of identifying 
assumptions. Forward-looking price expectations are likely to be more important in models of conversions between cropland and noncropland (e.g., Scott 2013) than for transitions between field crops.

To estimate the long-run marginal effect of expected price, it is useful to write the transition probabilities in matrix form as

$$
\boldsymbol{\Phi}_{i t}=\left[\begin{array}{ll}
\Phi_{i t}^{11} & \Phi_{i t}^{21} \\
\Phi_{i t}^{12} & \Phi_{i t}^{22}
\end{array}\right]
$$

and let $\boldsymbol{\xi}_{i t}$ denote a $2 \times 1$ vector that indicates the state of the process in year $t$. If the process is in state $j$, then $\boldsymbol{\xi}_{i t}$ has the value one in the $j^{\text {th }}$ row and zero in the other row. We can write $E\left(\boldsymbol{\xi}_{i t} \mid \boldsymbol{\xi}_{i, t-1}\right)=\boldsymbol{\Phi}_{i t} \boldsymbol{\xi}_{i, t-1}$. Holding the explanatory variables fixed at their values in period $t$, the vector of long-run state probabilities satisfies the following relationships:

$$
\begin{gathered}
\boldsymbol{\Phi}_{i t} \boldsymbol{\Pi}_{i t}=\boldsymbol{\Pi}_{i t}, \\
\boldsymbol{\Pi}_{i t}^{\prime} \mathbf{1}=1
\end{gathered}
$$

where $\boldsymbol{\Pi}_{i t}$ is the vector of long-run state probabilities and $\mathbf{1}$ is a vector of ones. Solving the system of equations in (17) and (18), the long-run probability of corn can be written as follows:

$$
\Pi_{i t}^{1}=\frac{\Phi_{i t}^{21}}{\Phi_{i t}^{21}+\left(1-\Phi_{i t}^{11}\right)}
$$

We estimate the effect on region-wide acreage from changes in the expected corn price by aggregating marginal effects across fields. The aggregate acres of corn in year $t$ is $C_{t}=$ $\sum_{i} a_{i} c_{i t}$, where $a_{i}$ denotes the fixed land area of field $i$-measured in acres. The long-run 
change in aggregate corn acres with respect to the expected price of corn is

(20) $\frac{\partial C_{L R}}{\partial p_{i t}^{c}}=\sum_{i} a_{i} \frac{\partial \Pi_{i t}^{1}}{\partial p_{i t}^{c}}$

The short-run change in aggregate corn acres with respect to the expected price of corn is

$$
\frac{\partial C_{S R}}{\partial p_{i t}^{c}}=\sum_{i} a_{i} \frac{\partial E\left(c_{i t} \mid \boldsymbol{\xi}_{i, t-1}\right)}{\partial p_{i t}^{c}}=\sum_{i} a_{i}\left(c_{i, t-1} \beta_{1 i}^{c}+\left(1-c_{i, t-1}\right) \beta_{2 i}^{c}\right)
$$

To estimate the short-run response to price from steady-state, we substitute $\Pi_{i t}^{1}$ for $c_{i, t-1}$ in equation (21). We estimate the short-run and long-run responses to the expected price of soybeans by replacing $p_{i t}^{c}$ with $p_{i t}^{s}$ in (20) and (21). We report these estimated short-run effects in elasticity form by multiplying by the mean expected price relative to the mean corn acreage in our sample.

At the extensive margin, we also estimate first-order Markov transition probabilities where the two states are (i) corn or soybeans and (ii) other crops. The transition probabilities are estimated as a function of an index of expected corn and soybean prices, an index of expected wheat and alfalfa prices, field characteristics ( $\mathbf{x}_{i}$ excluding spring rainfall), and a linear trend. The marginal effect of the price of corn on the probability of planting corn at the extensive margin is obtained by multiplying three components: (i) the derivative of the price index with respect to the price of corn, (ii) the marginal effect of the price index on the probability of planting corn or soybeans, and (iii) the probability of planting corn given that the field is planted to corn or soybeans obtained as a prediction from the rotational margin estimates.

Our transition probabilities in (14) and (15) are heterogeneous dynamic panel models with a small time series $(T)$ dimension. To elucidate the econometric challenges of estimating this model, we rewrite it as a single equation with a lagged dependent variable and price 
coefficients that are constant across states:

$$
\operatorname{Pr}\left(c_{i t}=1\right)=\lambda_{i}+\gamma_{i} c_{i, t-1}+\beta_{i}^{c} p_{i t}^{c}+\beta_{i}^{s} p_{i t}^{s}+\boldsymbol{\theta}_{i}^{\prime} \mathbf{x}_{i}+\kappa_{i} t
$$

OLS estimates of (22) are biased because the lagged dependent variable is correlated with the heterogeneous intercepts. Furthermore, when the coefficients are heterogeneous across fields, estimating a single coefficient for all fields (i.e., pooling) leads to biased estimates (Robertson and Symons 1992; Pesaran and Smith 1995). The bias from heterogeneous coefficients occurs because the error term in the pooled model is autocorrelated since it contains the lagged dependent variable and autocorrelated prices. For example, consider a field in which the probability of planting corn is more responsive to price than the average field. Higher than normal corn prices this year will generate a larger deviation from the average probability of planting corn for this field. Because prices are positively autocorrelated, this field also likely had a larger deviation from the average probability of planting corn for the field last year. Autocorrelated deviations from the average probability of planting corn bias the estimated coefficient on the lagged dependent variable.

If we had a panel with large $T$, then we could estimate separate coefficients for each field and then average across these coefficients to obtain an aggregate response. This "mean group estimator" (Pesaran and Smith 1995) is biased in short panels because each fieldlevel regression has too few observations to overcome the small-sample biases inherent in estimating dynamic models in short samples (Hsiao, Pesaran, and Tahmiscioglu 1999). Thus, we have a trade-off between allowing for heterogeneity but inducing the small- $T$ bias and pooling to reduce the small- $T$ problem but being left with the heterogeneity bias. We manage this trade-off by forming groups of similar fields and estimating separate coefficients for groups of similar fields (i.e., a "grouped coefficients" estimator). This approach reduces the small- $T$ bias by estimating regressions for large groups of fields and reduces bias from coefficient heterogeneity by only including relatively homogeneous fields in each regression. 
We use Major Land Resource Areas (MLRAs) from the Natural Resources Conservation Service (NRCS) to define groups of fields. NRCS defines Major Land Resource Areas as areas with similar soils, climate, and land uses. There are 33 MLRAs in the three states, but some of these are near the state borders and contain little area in our study region. We combine small MLRAs with neighboring MLRAs with similar characteristics to create 24 groups. We show these groups in figure 4 overlayed on maps of corn after corn and soybeans after soybeans in 2010 (a color figure is available in the online version of this article). The maps indicate that crop dynamics vary spatially by MLRA.

At the rotational margin, about a third of the fields were never planted to monoculture; they alternate between corn and soybeans throughout the sample period. At the extensive margin, about 90 percent of the fields are always planted to corn or soybeans. Such fields are unresponsive to prices in our sample period. To the extent that such fields are less responsive to price than other fields in the same MLRA, including them in a group-level regression induces a heterogeneity bias. Thus, at the rotational margin we divide the fields in each MLRA into two groups: (i) fields that were never planted to monoculture (i.e., always rotated between corn and soybeans) and (ii) fields that were planted to monoculture at least once. For fields that were never planted to monoculture, we impose the identifying restriction $\Phi_{i t}^{11}=0, \Phi_{i t}^{21}=1$. At the extensive margin we divide the fields into the following two groups: (i) fields that transitioned between corn or soybeans and other crops and (ii) fields that always planted corn or soybeans. For field that always planted corn or soybeans, we impose the identifying restriction that the probability of planting corn or soybeans is 1 regardless of the previous state.

We refer to our estimator as a "conditional grouped coefficients" estimator. It is a grouped coefficients estimator because our estimated coefficients are identical within $24 \times 2$ groups of similar fields as defined by 24 MLRAs and 2 transition groups. It is a conditional estimator because, within each MLRA, we estimate the model separately for two sets of fields. This conditional estimation approach is like the conditional likelihood approach used 
in discrete-choice models in that the parameters are only identified for fields that changed states (Heckman 1981). A similar estimation strategy was used by Bernard and Jensen (2004).

To estimate standard errors, we use a cluster bootstrap with 500 replications, where we cluster by year. Clustering by year permits cross-sectional (i.e., spatial) dependence between all of the fields for a given year, but assumes independence between years. We use the wild bootstrap because bootstrap methods that resample the regressors can be problematic when there are few clusters (Cameron, Gelbach, and Miller 2008). The wild bootstrap preserves the regressors but resamples the dependent variable using the OLS prediction and the residual with probability 0.5 and the negative of the residual with probability $0.5{ }^{19}$

\section{Econometric Results with Disaggregate Data}

First, we present our preferred econometric results using the conditional grouped coefficients methodology. Then we show results with commonly-used pooled estimators, which we argue are biased.

\section{Results with Conditional Grouped Coefficients}

Table 2 reports results for the aggregate acreage elasticities at the rotational and extensive margins. We find a small price response at the extensive margin - a change in the expected price of corn or soybeans causes a small change in the number of acres planted to corn or soybeans in Iowa, Illinois, and Indiana. In the supplementary online appendix, we examine the extensive margin response in more detail and show that a small response is consistent with aggregate data.

Panel A of table 2 reports corn acreage elasticities. Column (1) shows that, in the short run, a $10 \%$ increase in the price of corn results in a $4.0 \%$ increase in corn acreage, ceteris paribus. In the long run, a $10 \%$ increase in the price of corn results in a $2.9 \%$ increase in 
corn acreage, ceteris paribus. The cross-price elasticity is negative and large relative to the own-price elasticity since most of the acreage response is at the rotational margin.

Panel B of table 2 reports soybean acreage elasticities. We find that in the short run, a $10 \%$ increase in the price of soybeans results in a $3.6 \%$ increase in soybean acreage. In the long run, a $10 \%$ increase in the price of soybeans results in a $2.6 \%$ increase in soybean acreage. Note that the marginal effect for soybean acreage at the rotational margin is the negative of the marginal effect for corn acreage, but the elasticity differs in magnitude. The own-price elasticity is smaller than the cross-price elasticity for soybean acreage. Corn and soybean acreage may be more responsive to changes in the expected price of corn because in most regions corn is the more profitable crop in the rotation, ${ }^{20}$ while soybeans are grown to capture rotational benefits. Estimates by Chavas and Holt (1996) also indicate that the own-price elasticity is smaller than the cross-price elasticity for soybean acreage.

The relative difference in the short-run $\left(\varepsilon_{S R}\right)$ and long-run $\left(\varepsilon_{L R}\right)$ elasticities is reported in the last row of table 2 as $\frac{\varepsilon_{L R}-\varepsilon_{S R}}{\varepsilon_{L R}}$. This parameter is analogous to the coefficient on the lagged dependent variable in a regression with a single lagged dependent variable and is a convenient way to compare results across specifications. The total acreage response to a price shock is $37 \%$ larger in the short run than the long run. This result is consistent with our conceptual model of aggregate acreage dynamics with crop rotations, but stands in contrast to the previous literature on agricultural supply dynamics. In the supplementary online appendix, we show that our main results are robust to allowing for two-year memory in the econometric model.

Our regression estimates indicate substantial heterogeneity in the price response and acreage dynamics. The histograms in figure 5 show the distribution of short-run marginal effects of the expected price of corn (figure 5a), short-run marginal effects of the expected price of soybeans (figure 5b), and the dynamics (figure 5c) for fields that were planted to monoculture at least once. ${ }^{21}$ There are only a few cases where the coefficients on prices have 
the opposite sign from what is expected. Heterogeneity of the price response and dynamics suggests that pooled estimators are biased.

Table 3 reports average coefficients of the Markov transition models that are used to calculate the aggregate elasticities in table 2. Column (1) of table 3 reports coefficient estimates for the probability of planting corn given that the field was previously planted to corn. Column (2) reports estimates given that the field was previously planted to soybeans. The models are estimated separately for every MLRA. The standard deviation of coefficients across MLRAs is in brackets and the bootstrap standard error of the average coefficient is in parentheses.

Comparing columns (1) and (2) in table 3, farmers are much more responsive to changes in expected prices when corn was previously planted. If a field was previously planted to soybeans, then farmers are likely to plant corn even when prices change. Most of their adjustment to prices occurs on fields that were previously planted to corn where they choose whether to plant corn after corn or rotate with soybeans. The difference in the intercepts in columns (1) and (2) indicates that on average corn is more likely to be planted if the field was previously planted to soybeans rather than corn.

A large amount of rainfall in the spring tends to decrease the probability of planting corn - especially when soybeans were planted previously-because wet field conditions can delay corn planting. This partly explains the prevalence of soybeans after soybeans even though soybeans are generally considered less profitable than corn. The coefficients on the clay and silt content of the soil differ greatly between MLRAs (a large standard deviation), with the sign of the coefficient often differing between MLRAs. This result likely reflects nonlinear effects of the soil variables. For example, the effect of higher than average clay content in an MLRA with soils that have a large clay content may be different than the effect of higher than average clay content in an MLRA with soils that have a small clay content. Fields with greater slope have a lower probability of planting corn. Fields in a county with more irrigation were more likely to plant corn. However, the average coefficients 
for irrigation have large standard errors, perhaps because most counties in this region have little irrigation. The coefficient on the trend indicates that the probability of planting corn is increasing over time, holding prices constant; but the trend differs across space. The positive trend in planting corn if the field was previously planted to corn is consistent with the evidence reported by Duffy (2011) that the yield advantage of rotating corn and soybeans has been diminishing over time.

\section{Pooled Estimators}

Table 4 reports estimates of the aggregate corn acreage response to price with pooled estimators - that is, these results estimate a single coefficient for all fields. All of the estimates in table 4 only include the rotational margin response since we find negligible response at the extensive margin. Results in column (1) are from linear Markov transition probability models as in equations (14) and (15), but impose the same coefficients across all fields. Re-

sults in columns (2)-(4) are from a linear probability model with a single lagged dependent variable as in equation (22), but impose the same coefficients across all fields. The results in column (2), (3), and (4) are from Ordinary Least Squares (OLS), fixed effects (FE), and the Arellano-Bond estimator. Standard errors are clustered by year.

Results in columns (1) and (2) are similar indicating that there is a small difference in aggregate results if we estimate transition probabilities or a model with a lagged dependent variable. However, the elasticities in columns (1) and (2) of table 4 are substantially smaller than the elasticities in column (1) of table 2. As discussed previously, these pooled estimators are biased due to heterogeneous coefficients. The short-run elasticities increase slightly with the fixed effects estimator, but are still smaller than those in table 2. Arellano-Bond estimates are similar to fixed effects estimates, but the standard errors are very large.

Most of the acreage elasticities in table 4 are not statistically different from zero. The reason for the difference in standard errors in tables 2 and 4 is that results in table 2 use substantially more controls and this improves efficiency. For example, OLS estimates of the 
coefficients on prices are statistically significant if we included as controls MLRA dummy variables and interactions between the MLRAs and weather, soils, and the trend (results not reported).

The results in table 4 also indicate a larger relative difference between the short-run and long-run elasticities than our results in table 2. The pooled estimators are likely to overstate the difference in the short-run and long-run elasticity because they do not fully account for the correlation between the coefficient on price and the coefficient on the lagged dependent variable. We are interested in estimating the average (weighted by acreage) long-run effect, $\sum_{i} a_{i} \frac{\beta_{i}^{c}}{1-\gamma_{i}}$, rather than the long-run effect calculated from the average of the coefficients, $\frac{\bar{\beta}^{c}}{1-\bar{\gamma}}$, where $\gamma_{i}$ denotes the coefficient on the lagged dependent variable. These two concepts differ when the coefficients are correlated. For example, fields that are likely to maintain a corn-soybean rotation would have a coefficient on the lagged dependent variable that is close to -1 and a coefficient on price that is close to zero, whereas fields that are more likely to switch to monoculture have a smaller coefficient on the lagged dependent variable and larger coefficient on price. If an estimator does not allow coefficients to differ between these two types of fields, then the estimator overstates the difference between the short-run and long-run effect.

\section{Comparison with Aggregate Panel Data}

Aggregation of heterogeneous dynamic micro units can produce macro data with more persistence than the persistence of the average micro unit. Granger (1980) shows that the sum of heterogeneous $\mathrm{AR}(1)$ processes can produce a series with long memory. Trivedi (1985), Lewbel (1994), and Zaffaroni (2004) provide generalizations of this result. Empirically, this aggregation phenomenon has been used to explain univariate puzzles such as the persistent deviations of real exchange rates from purchasing power parity (Carvalho and Nechio 2011; Imbs et al. 2005) and the persistence of aggregate inflation (Altissimo, Mojon, and Zaffaroni 2009). 
In this section, we illustrate a different effect of aggregation-aggregation affects the bias of dynamic panel estimators due to coefficient heterogeneity. Pesaran and Smith (1995) show that the bias of pooled estimators in dynamic panels with heterogeneous coefficients depends on the degree of heterogeneity, the strength of the autocorrelation in the explanatory variables, and the variation of the explanatory variable relative to the variation of the noise (i.e., the signal-to-noise ratio). Aggregation will tend to reduce parameter heterogeneity, and thus reduce bias. However, aggregation will also increase the explanatory power of common factors (Granger 1987), and thus increase the signal-to-noise ratio and the bias from heterogeneous coefficients. ${ }^{22}$ Aggregation will tend to increase the bias from heterogeneous coefficients when the panels represent aggregates over similar micro units since aggregation has a minimal effect on reducing parameter heterogeneity, but increases the explanatory power of common factors.

Aggregation of corn and soybean acreage to the county level has a small effect on parameter heterogeneity due to the spatial autocorrelation of soils and climate. Aggregation does change the relative explanatory power of the variables. For example, the previous crop explains a large proportion of the variation in planting decisions at the field level. At the county level, the previous acreage planted to corn explains less of the variation in corn acreage while common factors, such as prices, explain a larger proportion of the variation in corn acreage. Thus, aggregation to the county level inflates the bias from coefficient heterogeneity since aggregation increases the explanatory power of autocorrelated common factors without substantially reducing parameter heterogeneity.

Table 5 reports estimates of the dynamic model of corn acreage with a single lagged dependent variable using county-level panel data. The crop acreage data are from the official county-level data reported by the National Agricultural Statistics Service (NASS). NASS uses the Cropland Data Layer to inform its county-level estimates, but also uses survey data. We use counties that had acreage data available for every year for the period 1999-2010 for Illinois and 2000-2010 for Iowa and Indiana. ${ }^{23}$ County-level expected prices are the average 
expected prices within each county from the field-level data. We also constructed our own county data by aggregating the Cropland Data Layer to the county level and obtained similar results. We only report estimates with official NASS county-level data.

The dependent variable is the acres planted to corn divided by the average number of acres planted to corn or soybeans for that county during the sample period. The normalization is needed since actual corn acreage depends largely on the size of the county. The dependent variable is a proportion, which is the aggregate analog of the linearly probability model.

Table 5 presents results from several commonly used dynamic panel estimators. The results in column (1) are fixed effects estimates. The results in column (2) are from the Anderson-Hsiao estimator that uses the second lagged level as an instrument for the lagged difference. The results in columns (3) and (4) are from the Arellano-Bond estimator (i.e., difference GMM) and results in column (5) are from the Blundell-Bond estimator (i.e., system GMM). In column (3) we use a maximum of 5 lags as instruments and in (4) and (5) we use all lags available as instruments. All of the results in table 5 are pooled estimates with a single lagged dependent variable, so the relative difference in the long-run and short-run elasticities $\left(\frac{\varepsilon_{L R}-\varepsilon_{S R}}{\varepsilon_{L R}}\right)$ is simply the coefficient on the lagged dependent variable.

The fixed effects result in column (1) of table 5 shows that the bias from ignoring coefficient heterogeneity is so large that pooled estimates indicate the response to a price shock is smaller in the short run than in the long run-thus, creating the illusion of partial adjustment. The fixed effects estimator gives a coefficient on the lagged dependent variable of 0.19 with county-level data. For comparison, the analogous estimate with field-level data using conditional grouped coefficients is $-0.39 .{ }^{24}$ Furthermore, standard theory that assumes only the intercept is heterogeneous would expect the positive coefficient in table 5 to underestimate the true coefficient, when it actually substantially overestimates the true coefficient.

The positive bias of the coefficient on the lagged dependent variable occurs because it captures positive autocorrelation in prices and the trend. For example, if price response is 
larger in a particular county, then that county is also likely to have had a larger corn acreage in the previous year since prices are positively autocorrelated. There are also likely to be other common factors that are omitted from our analysis. These omitted common factors will have a small effect on estimates with field-level data since they explain a small proportion of the variation in field-level planting decisions. However, omitted common factors will have a larger effect on estimates with county-level data because they explain a larger proportion of the variation in aggregate crop acreage and there may be substantial heterogeneity in the response to these common factors across counties.

Commonly used dynamic panel estimators do little to alleviate the severe bias of fixed effects. The coefficient on the lagged dependent variable is positive for every dynamic panel estimator with county-level data, except the Arellano-Bond estimator when all lags are used as instruments (column 4 of table 5). However, if a maximum of 5 lags are used as instruments, then the coefficient on the lagged dependent variable is 0.20 (column 3 ). ${ }^{25}$

To reinforce our point that aggregation over similar fields is the cause of the bias in county-level estimates, we create pseudo counties by randomly assigning the fields in our sample to 100 different groups and aggregating within the groups. Because the groups are randomly assigned and include a large number of fields, the parameter heterogeneity is mostly removed by the aggregation. Pooled OLS estimates with this group-level data give a negative coefficient on the lagged dependent variable (column 6 of table 5). The elasticities are similar, but slightly smaller than our conditional grouped coefficient estimates with fieldlevel data in table 2 . The results from the randomly grouped data provide evidence that the difference in estimates with county-level and field-level data is mostly due to the bias from heterogeneous responses to autocorrelated factors rather than the aggregation of dynamic processes per se. 


\section{Conclusion}

This article provides estimates of short-run and long-run elasticities of supply for corn and soybeans, the crops with more acreage than any other in the United States. These supply elasticities are central for understanding world food prospects and the environmental consequences of land use change, which have garnered substantial attention recently due to expanding ethanol production. We use more than 8 million observations that include every field in Iowa, Illinois, and Indiana over an 11 year period - these three states produce roughly $15 \%$ of the world's corn and soybeans. Our analysis of supply response exploits recent demand shocks in corn and soybean prices caused by strong global commodity demand and the U.S. policy to convert corn to ethanol for fuel use (Carter, Rausser, and Smith 2013).

We show that field-level dynamics imply that aggregate acreage of a crop responds to price shocks more in the short run than in the long run when that crop is grown in rotation with another crop. For corn and soybeans, we estimate that the short-run elasticity of planted-acreage with respect to price exceeds its long-run counterpart by 37 percent. Our results differ from all previous estimates because we use a rich set of field-level data to appropriately model the dynamics of cropping decisions from crop rotations and account for coefficient heterogeneity across space.

We estimate an own-price elasticity of 0.29 and a cross-price elasticity of -0.22 for corn acreage in the long run. Our estimates for the Corn Belt indicate that almost all of the acreage response to price occurs through substitution between corn and soybeans, rather than changes in the total acreage planted to corn or soybeans. Roberts and Schlenker (2013) also estimate a small extensive margin response of corn, soybean, wheat, and rice acreage (taken together) to price in the United States as a whole. After accounting for set-aside

programs, they find a statistically insignificant extensive margin response to price (see their table 3). Barr et al. (2011) also estimate a small price elasticity of the total acreage of major crops in the United States as a whole. 
An important topic for future research is to extend our methods to understand supply response dynamics in other production regions of the United States and the world. Research using crop data from satellite imagery is rapidly becoming feasible for other regions. For example, the Cropland Data Layer has been made available for the continental United States since 2008. Future research could also analyze the dynamics of aggregate supply resulting from different dynamics in different regions. Another topic for future research is to incorporate forward-looking price expectations into the conceptual and econometric models.

We also illustrate that heterogeneity in the response to autocorrelated factors can create the illusion of partial adjustment or inertia in dynamic panel estimates. We obtain the expected result that the short-run response to price is larger than the long-run response using field-level data and accounting for coefficient heterogeneity using Major Land Resource Areas. Using county-level data, results from popular dynamic panel estimators support the partial adjustment model. The bias from coefficient heterogeneity is amplified with county-level data because prices explain a greater proportion of variation in corn acreage at the county level and parameter heterogeneity persists at the county level due to spatial autocorrelation. These results suggest that caution is warranted when inferring inertia from dynamic panel estimators, especially when panels represent aggregates across correlated micro units. 


\section{References}

Altissimo, F., B. Mojon, and P. Zaffaroni. 2009. "Can Aggregation Explain the Persistence of Inflation?" Journal of Monetary Economics 56:231-241.

Askari, H., and J.T. Cummings. 1977. "Estimating Agricultural Supply Response with the Nerlove Model: A Survey." International Economic Review 18:257-292.

Barr, K.J., B.A. Babcock, M.A. Carriquiry, A.M. Nassar, and L. Harfuch. 2011. "Agricultural Land Elasticities in the United States and Brazil." Applied Economic Perspectives and Policy 33:449-462.

Bernard, A.B., and J.B. Jensen. 2004. "Why Some Firms Export." Review of Economics and Statistics 86:561-569.

Berry, S., and W. Schlenker. 2011. "Technical Report for the ICCT: Empirical Evidence on Crop Yield Elasticities." Technical report, http://www .theicct.org/sites/default/ files/publications/berry_schlenker_cropyieldelasticities_sep2011.pdf.

Boryan, C., Z. Yang, R. Mueller, and M. Craig. 2011. "Monitoring US Agriculture: The US Department of Agriculture, National Agricultural Statistics Service, Cropland Data Layer Program." Geocarto International, pp. 1-18.

Cameron, A.C., J.B. Gelbach, and D.L. Miller. 2008. "Bootstrap-Based Improvements for Inference with Clustered Errors." Review of Economics and Statistics 90:414-427.

Carter, C.A., G. Rausser, and A. Smith. 2013. "Commodity Storage and the Market Effects of Biofuel Policies." Working paper, Available at http://asmith.ucdavis.edu.

Carvalho, C., and F. Nechio. 2011. "Aggregation and the PPP Puzzle in a Sticky-Price Model." American Economic Review 101:2391-2424.

Chavas, J.P., and M.T. Holt. 1996. "Economic Behavior Under Uncertainty: A Joint Analysis of Risk Preferences and Technology." Review of Economics and Statistics 78:329-335. 
de Menezes, T.A., and M.G. Piketty. 2012. "Towards a Better Estimation of Agricultural Supply Elasticity: The Case of Soya Beans in Brazil." Applied Economics 44:4005-4018.

Donner, S.D., and C.J. Kucharik. 2008. "Corn-based Ethanol Production Compromises Goal of Reducing Nitrogen Export by the Mississippi River." Proceedings of the National Academy of Sciences 105:4513-4518.

Duffy, M. 2011. "Continuous Corn versus Corn/Soybeans: Do the Relative Prices Change the Profit Comparison?" Ag Decision Maker Newsletter, Iowa State University.

Eckstein, Z. 1984. "A Rational Expectations Model of Agricultural Supply." Journal of Political Economy 92:1-19.

Granger, C.W.J. 1987. "Implications of Aggregation with Common Factors." Econometric Theory 3:208-222.

—. 1980. "Long Memory Relationships and the Aggregation of Dynamic Models." Journal of Econometrics 14:227-238.

Heckman, J. 1981. "The Incidental Parameters Problem and the Problem of Initial Conditions in Estimating a Discrete TimeDiscrete Data Stochastic Process." In C. Manski and D. McFadden, eds. The Structural Analysis of Discrete Data. Cambridge, MA: MIT Press.

Hendricks, N.P., J.P. Janzen, and A. Smith. 2013. "Futures Prices in Supply Analysis Reconsidered." Paper presented at AAEA annual meeting, Washington D.C., 4-6 August.

Hennessy, D.A. 2006. "On Monoculture and the Structure of Crop Rotations." American Journal of Agricultural Economics 88:900-914.

Hsiao, C., M.H. Pesaran, and A.K. Tahmiscioglu. 1999. "Bayes Estimation of Short-Run Coefficients in Dynamic Panel Data Models." In C. Hsiao, K. Lahiri, L.-F. Lee, and M. H. Pesaran, eds. Analysis of Panels and Limited Dependent Variable Models. Cambridge, UK: Cambridge University Press. 
Imbs, J., H. Mumtaz, M.O. Ravn, and H. Rey. 2005. "PPP Strikes Back: Aggregation and the Real Exchange Rate." Quarterly Journal of Economics 120:1-43.

Lewbel, A. 1994. "Aggregation and Simple Dynamics." American Economic Review 84:905918.

Lichtenberg, E. 2002. "Agriculture and the Environment." In B. L. Gardner and G. C. Rausser, eds. Handbook of Agricultural Economics. Elsevier, vol. 2, pp. 1249 - 1313.

Lichtenberg, E., and D. Zilberman. 1986. "The Welfare Economics of Price Supports in U.S. Agriculture." American Economic Review 76:1135-1141.

Livingston, M.J., M.J. Roberts, and Y. Zhang. 2013. "Optimal Sequential Plantings of Corn and Soybeans Under Price Uncertainty." Working paper, Available at: http: //www2.hawaii.edu/ mjrobert/main/Working_Papers.html.

Nerlove, M. 1958. The Dynamics of Supply: Estimation of Farmers' Response to Price. Baltimore, MD: The Johns Hopkins Press.

Pesaran, M.H., and R. Smith. 1995. "Estimating Long-Run Relationships from Dynamic Heterogeneous Panels." Journal of Econometrics 68:79-113.

Roberts, M.J., and W. Schlenker. 2013. "Identifying Supply and Demand Elasticities of Agricultural Commodities: Implications for the US Ethanol Mandate." American Economic Review 103:2265-2295.

Robertson, D., and J. Symons. 1992. "Some Strange Properties of Panel Data Estimators." Journal of Applied Econometrics 7:175-189.

Roodman, D. 2009. "A Note on the Theme of Too Many Instruments." Oxford Bulletin of Economics and Statistics 71:135-158.

Rust, J. 1987. "Optimal Replacement of GMC Bus Engines: An Empirical Model of Harold Zurcher." Econometrica 55:999-1033. 
Scott, P.T. 2013. "Dynamic Discrete Choice Estimation of Agricultural Land Use." Working paper, Available at: http://www.ptscott.com/.

Searchinger, T., R. Heimlich, R.A. Houghton, F. Dong, A. Elobeid, J. Fabiosa, S. Tokgoz, D. Hayes, and T.H. Yu. 2008. "Use of U.S. Croplands for Biofuels Increases Greenhouse Gases Through Emissions from Land-Use Change." Science 319:1238-1240.

Tegene, A., W.E. Huffman, and J.A. Miranowski. 1988. "Dynamic Corn Supply Functions: A Model with Explicit Optimization." American Journal of Agricultural Economics 70:103111.

Trivedi, P.K. 1985. "Distributed Lags, Aggregation and Compounding: Some Econometric Implications." The Review of Economic Studies 52:19-35.

Zaffaroni, P. 2004. "Contemporaneous Aggregation of Linear Dynamic Models in Large Economies." Journal of Econometrics 120:75-102. 


\section{Notes}

${ }^{1}$ We define the long run as 5-10 years. Given a sample period of 11 years, we do not claim to estimate responses with an even longer horizon.

${ }^{2}$ The planted acreage elasticity is not the same as the supply elasticity if average yields are affected by price, but Berry and Schlenker (2011) estimate yield-price elasticities near zero for the United States.

${ }^{3} \mathrm{~A}$ long time series of crop data is available for the United States, but acreage decisions were highly distorted by government policies prior to the 1996 Farm Bill, suggesting caution about estimating parameters useful for current applications from the long time series.

${ }^{4}$ These assumptions simplify the conceptual model so that (i) we can solve the model for an individual field rather than at the farm level and (ii) the optimal cropping decision is a repeating crop rotation.

${ }^{5}$ We could relax this assumption slightly by assuming that harvest-time prices are iid random and the planting-time expectation of harvest prices is constant across years. Introducing more general forms of price uncertainty creates an option value in the rotation decision that we ignore here for simplicity.

${ }^{6}$ Note that $\langle c s\rangle$ is equivalent to $\langle s c\rangle$.

${ }^{7}$ We could instead conceptualize yield as containing an iid random component and define $y_{i}^{j}(\cdot)$ to be the expected yield functions. To retain the simplicity of our solution, this conceptualization would require yield to be independent of price or the covariance between yield and price to be constant.

${ }^{8}$ This assumption makes the model tractable by making the accounting profits linear in output and input prices (Hennessy 2006).

${ }^{9}$ In other words, $\tilde{\pi}_{i}^{c c}=p_{i}^{c} y_{i}^{c}\left(\tilde{x}_{i}^{c c}\right)-w_{i} \tilde{x}_{i}^{c c}$, where $\tilde{x}_{i}^{c c}$ is optimal input use when planting corn after corn.

${ }^{10}$ The assumption in figure 1 is that if other land uses are converted to corn or soybeans, then these fields are planted to continuous soybeans. Of course, other land uses may also be converted to plant corn-soybeans or continuous corn. Our empirical results indicate that most of the changes in corn and soybean acreage occurs between corn and soybeans so that is the focus of the model here.

${ }^{11}$ In the case of two-year memory, the difference between the short-run and long-run response also occurs due to fields converting from a corn-soybean rotation to a corn-corn-soybean rotation. All fields that switch from corn-soybeans to corn-corn-soybeans due to an increase in the relative price are planted to corn in the short run, but in the long run only $2 / 3$ of these fields are planted to corn.

${ }^{12}$ The Cropland Data Layer can be viewed and downloaded at http://nassgeodata.gmu.edu/CropScape/. For details on the methodology of constructing the Cropland Data Layer see Boryan et al. (2011).

${ }^{13}$ We only include points corresponding to Common Land Units larger than 15 acres in the empirical analysis. Further details on constructing the crop data are provided in the supplementary online appendix. 
${ }^{14}$ Basis is a generic term for a price difference across space or time. In this case, basis refers to the difference between the local price at harvest time and the expiring futures price, which typically represents a price along the Illinois River.

${ }^{15}$ Monthly price data for our sample period are only available for Iowa. We obtain these data from NASS.

${ }^{16}$ In 2008, corn after corn increased again, not because more fields shifted to a continuous corn rotation, but because half of the fields that shifted from corn-soybeans to corn-corn-soybeans or continuous corn were soybeans in 2006 so they did not plant corn after corn until 2008.

${ }^{17}$ Aggregating our field-level dataset-including CLUs less than 15 acres-we obtain corn and soybean acreage similar to official NASS data, but underestimate the acreage of other crops.

${ }^{18}$ Another method is to specify a dynamic nested logit model, but this specification is likely to unnecessarily complicate the estimation since the extensive margin response is small.

${ }^{19}$ At the extensive margin, some bootstrap replications indicate that the relative difference between the short-run and long-run elasticities, $\frac{\varepsilon_{L R}-\varepsilon_{S R}}{\varepsilon_{L R}}$, is outside the unit circle. Thus, we report the standard error on the relative difference in elasticities at the extensive margin as the standard deviation of bootstrap replications after trimming those replications outside of the unit circle.

${ }^{20}$ According to crop budgets from University of Illinois extension services, the return from corn after soybeans was roughly $\$ 50-125$ more per acre than soybeans after corn in 2012 . The 2012 crop budgets are available at http://www.farmdoc.illinois.edu/manage/2012_crop_budgets.pdf.

${ }^{21}$ For those fields that were never planted to monoculture, the estimated short-run and long-run marginal effects are zero.

${ }^{22}$ We replicate the bias formulas of Pesaran and Smith (1995) and formalize this intuition in the supplementary online appendix.

${ }^{23}$ There were 11 counties that only had data available for a portion of the sample period. If we include these counties in the analysis, then the fixed effects estimate of the coefficient on the lagged dependent variable is biased upward even further.

${ }^{24}$ Pooled fixed effects with field-level data and a single lagged dependent variable gives a coefficient on the lagged dependent variable of -0.68 (table 4). However, we argue that the coefficient on the lagged dependent variable in pooled fixed effects is likely biased downward with field-level data.

${ }^{25}$ If less than nine lagged levels are used as instruments, then the coefficient on the lagged dependent variable is positive and if nine or more lags are used as instruments then the coefficient is negative. 
Figures

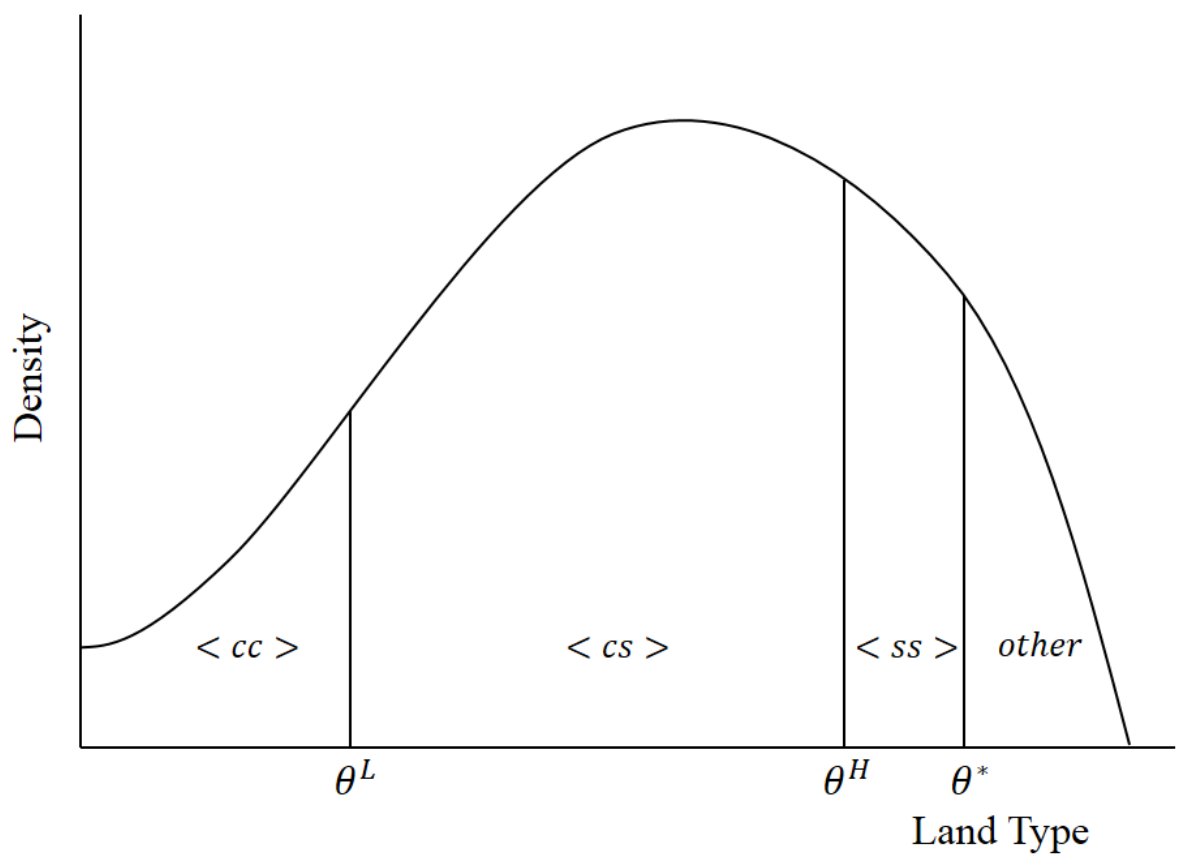

Figure 1: Illustration of land heterogeneity and crop rotations 

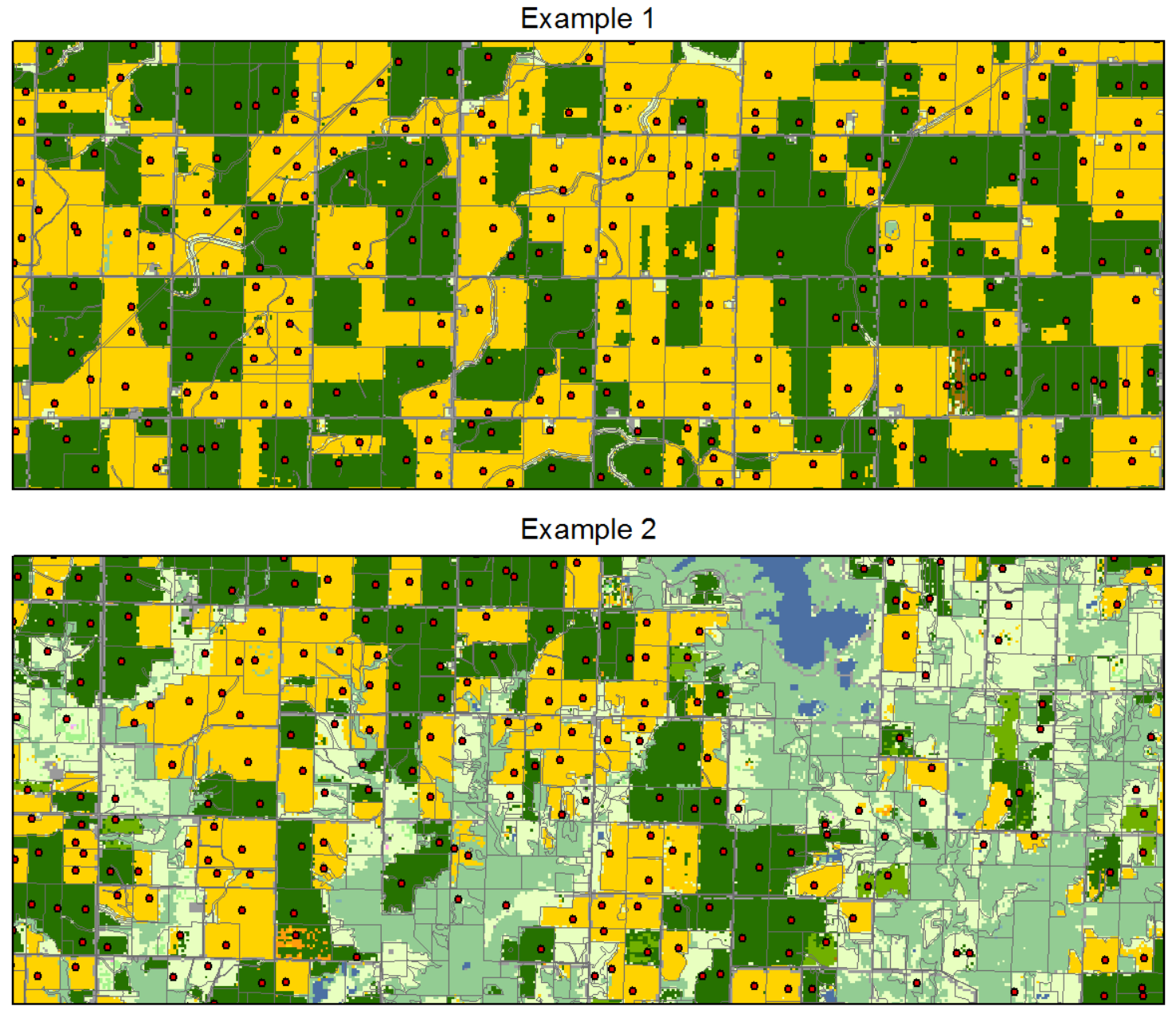

Legend

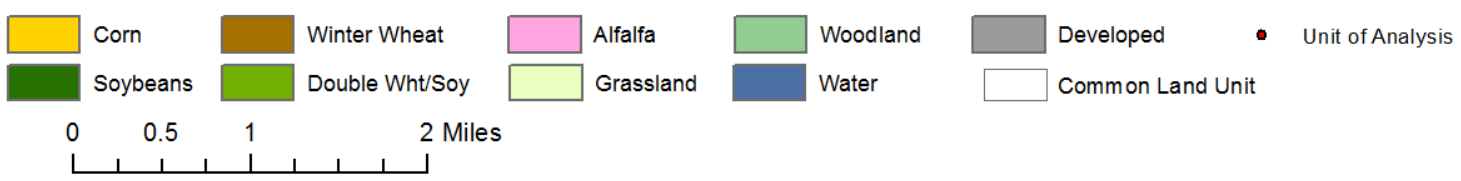

Figure 2: Example of Cropland Data Layer with Common Land Unit boundaries and points used as the unit of analysis for the econometric model

Notes: The figure shows two examples of the raw data used to construct the field-level panel of crop data. Example 1 is a region planted almost exclusively to corn and soybeans. Example 2 is a region with areas of woodland and grassland interspersed with corn and soybeans. The classifications of each pixel are from the 2010 Cropland Data Layer (CDL). The light gray lines are Common Land Unit (CLU) boundaries. The red points are diagonally offset from the centroid of CLUs that are larger than 15 acres. The panel of crop data corresponds to the crop classification at each of these points over time. This figure is available in color in the online version of the article. 


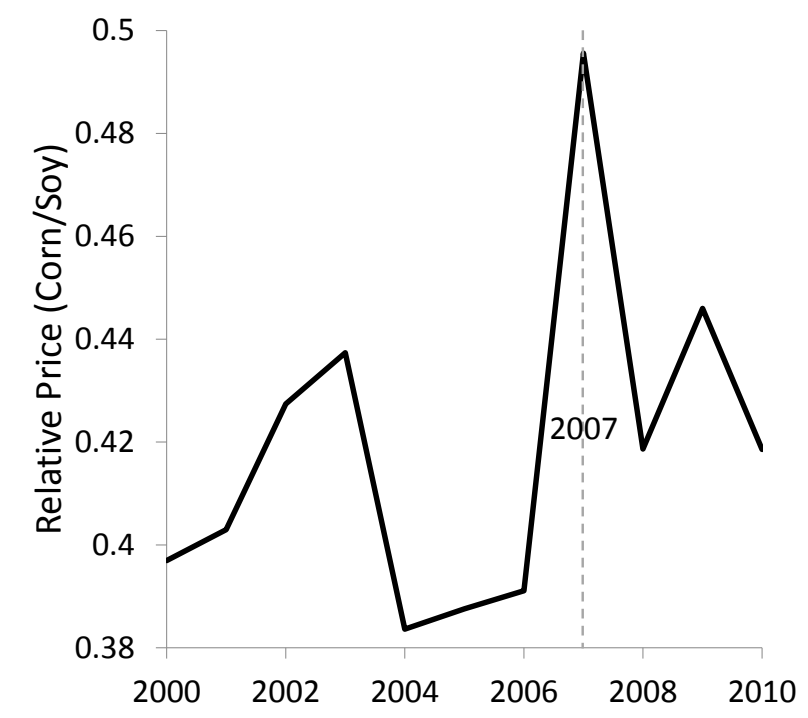

(a) Relative expected price of corn to soybeans

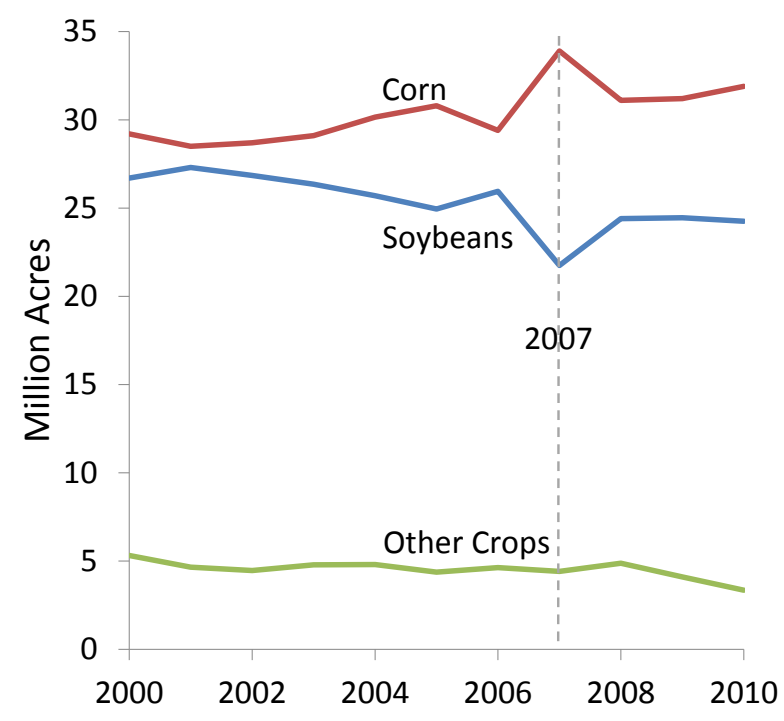

(b) Crop acreage

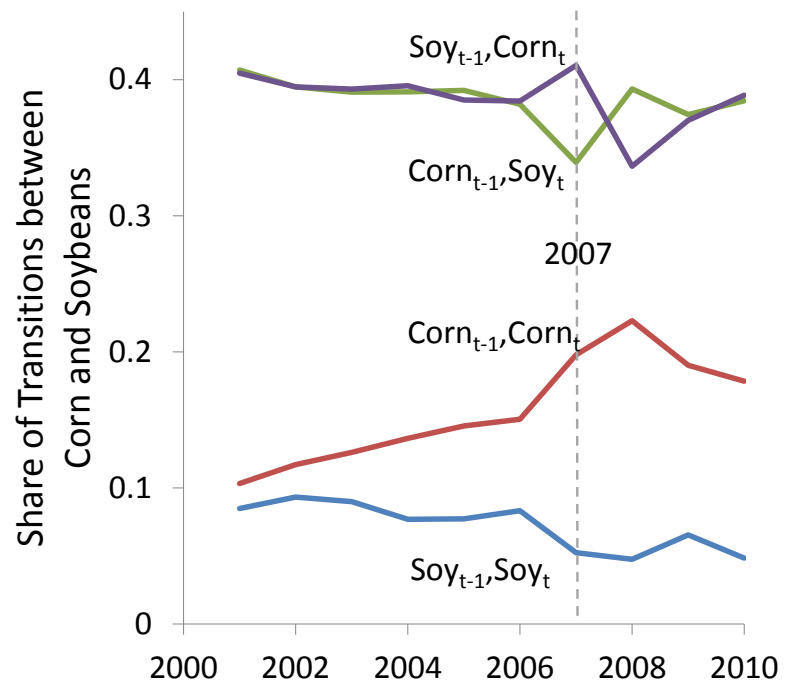

(c) Crop transitions

Figure 3: Relative expected prices, crop acreage, and crop transitions in Iowa, Illinois, and Indiana (2000-2010)

Notes: Expected prices are the sum a futures price, an expected basis, and an expected loan deficiency payment. The expected basis for the graph in panel (a) is the average expected basis across the entire region. The crop acreage in panel (b) is the sum of state-level data from NASS. Aggregate crop transitions in panel (c) were calculated by the authors using data from the Cropland Data Layer. Crop transitions were aggregated across all of the fields used in our econometric analysis. 


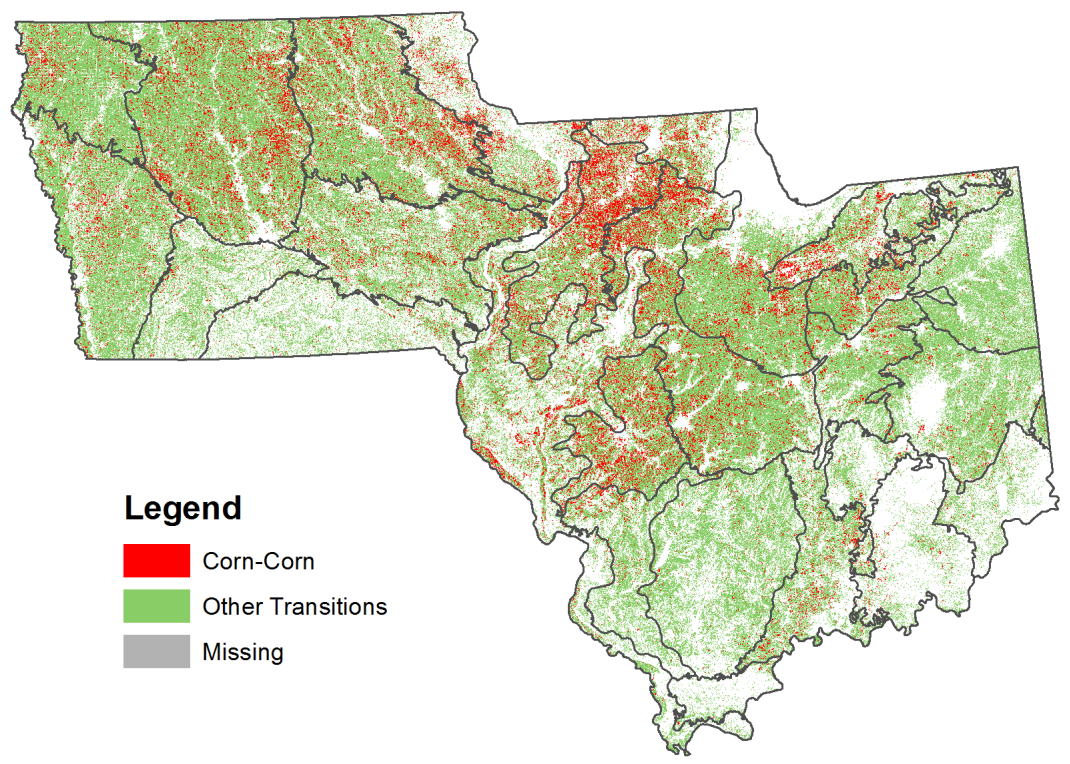

(a) Corn in 2009 and corn in 2010

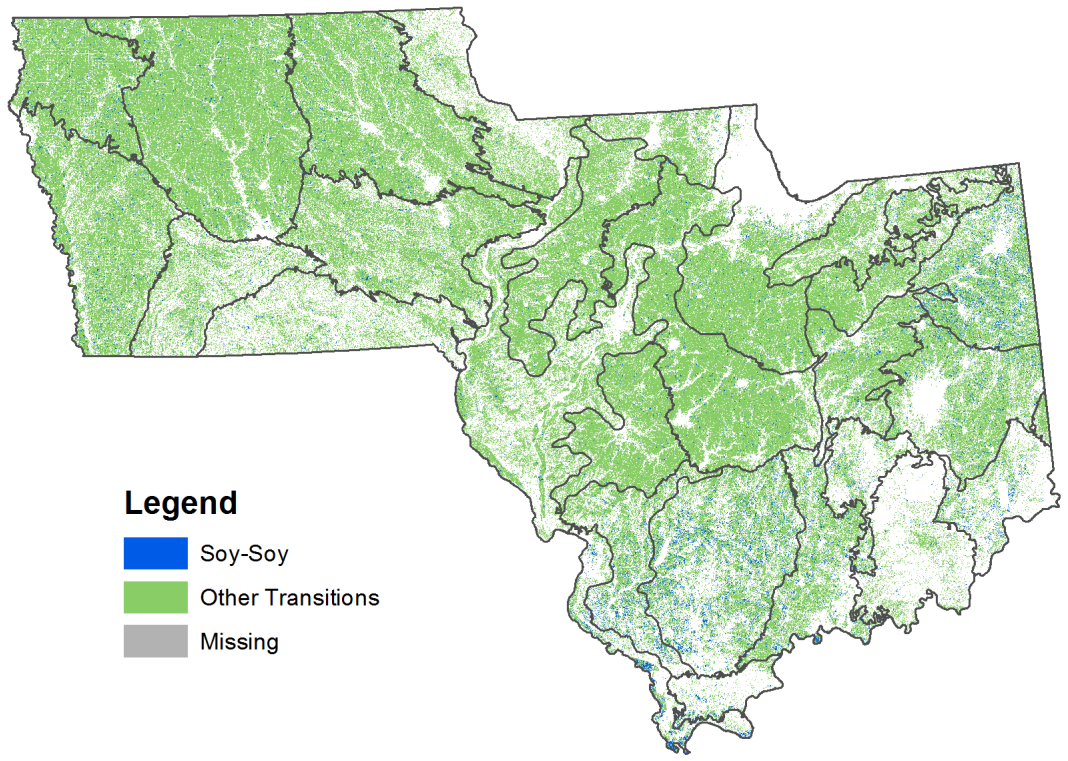

(b) Soybeans in 2009 and soybeans in 2010

\section{Figure 4: Major Land Resource Areas (MLRAs) overlayed on maps of corn after corn and soybeans after soybeans in 2010}

Notes: The map in panel (a) shows Common Land Units that were classified as corn in 2009 and corn in 2010 in red and other transitions in green. The map in panel (b) shows Common Land Units that were classified as soybeans in 2009 and soybeans in 2010 in blue and other transitions in green. The white area within the region indicates areas that were other land uses in 2009 and 2010 (e.g., urban areas, forest, and pasture). The dark lines indicate the borders of the 24 Major Land Resource Areas (MLRAs) that we use to specify similar groups of fields. Most of the MLRAs represent a single area on the map. In some cases though, two noncontiguous areas are identified as the same MLRA. This figure is available in color in the online version of the article. 


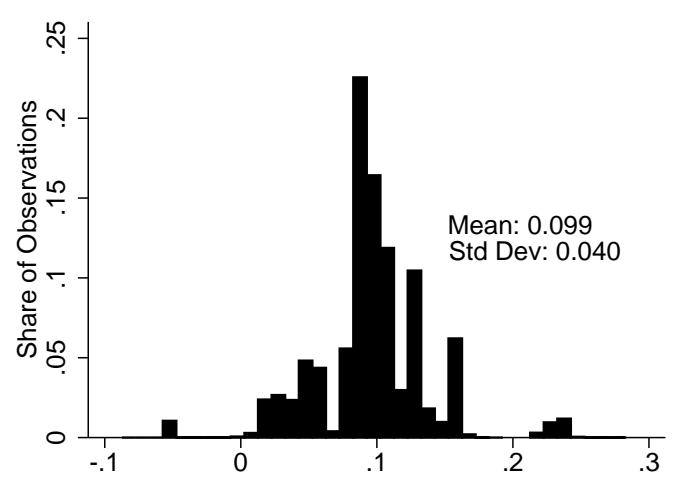

(a) Short-run marginal effect of expected corn price

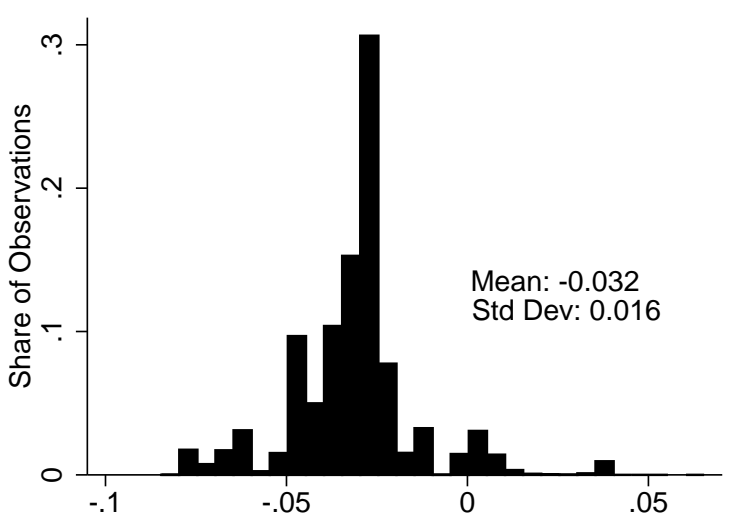

(b) Short-run marginal effect of expected soybean price

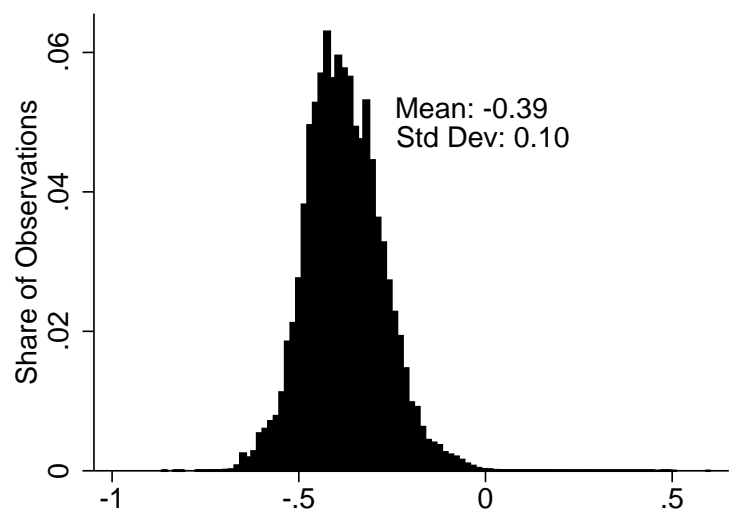

(c) Relative difference in long-run and short-run elasticities $\left(\frac{\varepsilon_{L R}-\varepsilon_{S R}}{\varepsilon_{L R}}\right)$

\section{Figure 5: Distribution of marginal effects and dynamics of the fields that were planted to monoculture at least once}

Notes: The histograms show how short-run marginal effects and dynamics vary across fields from estimates of the linear Markov transition probability models as specified in equations (14) and (15). The histograms show marginal effects across the Major Land Resource Area (MLRA) for those fields that were planted to monoculture at least once. For those fields that were never planted to monoculture, the estimated short-run and long-run marginal effects are zero. The histograms represent the distribution of field-specific marginal effects from equations (20) and (21) calculated across roughly 5.8 million observations. Panel A is a histogram (bin size $=0.01$ ) of the short-run marginal effects of the expected price of corn. Panel B is a histogram (bin size $=0.005$ ) of the short-run marginal effects of the expected price of soybeans. Panel $\mathrm{C}$ is a histogram (bin size $=0.015)$ of the relative difference in the long-run $\left(\varepsilon_{L R}\right)$ and short-run $\left(\varepsilon_{S R}\right)$ elasticities that is analogous to the coefficient on a single lagged dependent variable. 


\section{Tables}

Table 1: Descriptive Statistics of the Estimation Samples

\begin{tabular}{lcc}
\hline \hline & Mean & Std. Dev. \\
\hline Panel A. Rotational Margin Sample & $(\mathrm{N}=8,369,302)$ \\
Corn & 0.54 & 0.50 \\
Soybeans & 0.46 & 0.50 \\
Corn after Corn & 0.16 & 0.36 \\
Corn after Soybeans & 0.39 & 0.49 \\
Soybeans after Corn & 0.39 & 0.49 \\
Soybeans after Soybeans & 0.07 & 0.26 \\
Never Monoculture & 0.32 & 0.47 \\
Monoculture at Least Once & 0.68 & 0.47 \\
& & \\
Expected Price of Corn $(\$ /$ bu $)$ & 3.18 & 0.86 \\
Expected Price of Soybeans $\$$ /bu) & 7.56 & 1.85 \\
Large Spring Rainfall & 0.25 & 0.43 \\
Share Clay & 0.27 & 0.07 \\
Share Silt & 0.51 & 0.15 \\
Slope & 2.94 & 3.34 \\
Share Irrigated & 0.01 & 0.04 \\
& & \\
Panel B. Extensive Margin Sample & $(\mathrm{N}=8,753,448)$ \\
Corn or Soybeans & 0.98 & 0.13 \\
Other Crops & 0.02 & 0.13 \\
Always Corn or Soybeans & 0.89 & 0.32 \\
Other Crop at Least Once & 0.11 & 0.32 \\
& & \\
Index of Corn and Soybean Prices & 1.21 & 0.31 \\
Index of Alfalfa and Wheat Prices & 1.27 & 0.29 \\
Share Clay & 0.27 & 0.07 \\
Share Silt & 0.51 & 0.15 \\
Slope & 2.99 & 3.40 \\
\hline
\end{tabular}

Notes: Panel A gives descriptive statistics for the rotational margin sample - observations (field-year pairs) that were classified as corn or soybeans in two consecutive years. A field was never planted to monoculture if corn after corn and soybeans after soybeans were never observed. Panel B gives descriptive statistics for the extensive margin sample - observations that were classified as a crop but where the field was classified as corn or soybeans at least once during the sample period and for which there is a crop observed in two consecutive years. 

Table 2: Aggregate Acreage Elasticities from Conditional Grouped Coefficients
Regressions using Field-level Data

\begin{tabular}{|c|c|c|c|}
\hline & $\begin{array}{c}\text { Rotational } \\
(1) \\
\end{array}$ & $\begin{array}{c}\text { Extensive } \\
(2)\end{array}$ & $\begin{array}{c}\text { Total } \\
(3)\end{array}$ \\
\hline \multicolumn{4}{|c|}{$\begin{array}{l}\text { Panel A. Corn Acreage Elasticities } \\
\text { Own-Price }\end{array}$} \\
\hline Short-run & $\begin{array}{c}0.40^{* *} \\
(0.093)\end{array}$ & $\begin{array}{c}0.004 \\
(0.004)\end{array}$ & $\begin{array}{c}0.40^{* *} \\
(0.093)\end{array}$ \\
\hline Long-run & $\begin{array}{c}0.29^{* *} \\
(0.068)\end{array}$ & $\begin{array}{c}0.006 \\
(0.004)\end{array}$ & $\begin{array}{c}0.29^{* *} \\
(0.068)\end{array}$ \\
\hline \multicolumn{4}{|l|}{ Cross-Price } \\
\hline Short-run & $\begin{array}{l}-0.31^{* *} \\
(0.103)\end{array}$ & $\begin{array}{c}0.002 \\
(0.003)\end{array}$ & $\begin{array}{l}-0.30^{* *} \\
(0.103)\end{array}$ \\
\hline Long-run & $\begin{array}{l}-0.22^{* *} \\
(0.075)\end{array}$ & $\begin{array}{c}0.003 \\
(0.003)\end{array}$ & $\begin{array}{l}-0.22^{* *} \\
(0.075)\end{array}$ \\
\hline \multicolumn{4}{|c|}{$\begin{array}{l}\text { Panel B. Soybean Acreage Elasticities } \\
\text { Own-Price }\end{array}$} \\
\hline Short-run & $\begin{array}{c}0.36^{* *} \\
(0.121)\end{array}$ & $\begin{array}{c}0.002 \\
(0.003)\end{array}$ & $\begin{array}{l}0.36^{* *} \\
(0.121)\end{array}$ \\
\hline Long-run & $\begin{array}{c}0.26^{* *} \\
(0.088)\end{array}$ & $\begin{array}{c}0.003 \\
(0.003)\end{array}$ & $\begin{array}{c}0.26^{* *} \\
(0.088)\end{array}$ \\
\hline \multicolumn{4}{|l|}{ Cross-Price } \\
\hline Short-run & $\begin{array}{l}-0.46^{* *} \\
(0.109)\end{array}$ & $\begin{array}{c}0.003 \\
(0.004)\end{array}$ & $\begin{array}{l}-0.46^{* *} \\
(0.109)\end{array}$ \\
\hline Long-run & $\begin{array}{l}-0.33^{* *} \\
(0.080)\end{array}$ & $\begin{array}{c}0.005 \\
(0.004)\end{array}$ & $\begin{array}{l}-0.33^{* *} \\
(0.080)\end{array}$ \\
\hline$\frac{\varepsilon_{L R}-\varepsilon_{S R}}{\varepsilon_{L R}}$ & $\begin{array}{l}-0.39^{* *} \\
(0.012)\end{array}$ & $\begin{array}{c}0.35 \\
(0.233)\end{array}$ & $\begin{array}{c}-0.37^{* *} \\
(0.013)\end{array}$ \\
\hline
\end{tabular}

Notes: Elasticities are calculated as the elasticity of the average marginal effect across all fields, weighted by the size of the fields. Results in column (1) are from linear Markov transition probability models as specified in equations (14) and (15). The linear probability models are estimated separately for each Major Land Resource Area (MLRA). Within each MLRA, the model is estimated only for fields where monoculture was observed at least once. The price response is assumed to be zero for those fields that were never planted to monoculture. Results in column (2) are from Markov transition models between corn or soybeans and other crops. The model is estimated separately for each MLRA. Within each MLRA, the model is estimated for those fields that transitioned between corn or soybeans and other crops. The price response is assumed to be zero for fields that always planted corn or soybeans. The last row gives the relative difference in the long-run $\left(\varepsilon_{L R}\right)$ and short-run $\left(\varepsilon_{S R}\right)$ elasticities that is analogous to the coefficient on a single lagged dependent variable. Standard errors are clustered by year and estimated with a wild bootstrap.

${ }^{* *}$ Significant at the 5 percent level.

${ }^{*}$ Significant at the 10 percent level. 
Table 3: Average Coefficients of Transition Probabilities for Fields that were Planted to Monoculture at Least Once

\begin{tabular}{lcc}
\hline \hline & $\begin{array}{c}\text { Previously } \\
\text { Corn } \\
(1)\end{array}$ & $\begin{array}{c}\text { Previously } \\
\text { Soybeans } \\
(2)\end{array}$ \\
\hline Expected Corn Price & $0.119^{* *}$ & $0.072^{* *}$ \\
& {$[0.038]$} & {$[0.070]$} \\
& $(0.033)$ & $(0.023)$ \\
Expected Soy Price & $-0.043^{* *}$ & $-0.018^{*}$ \\
& {$[0.021]$} & {$[0.027]$} \\
Large Spring Rainfall & $(0.015)$ & $(0.008)$ \\
& -0.007 & $-0.043^{* *}$ \\
Share Clay & {$[0.045]$} & {$[0.040]$} \\
& $(0.005)$ & $(0.004)$ \\
Share Silt & $-0.313^{* *}$ & $0.033^{*}$ \\
& {$[0.207]$} & {$[0.206]$} \\
Slope & $(0.028)$ & $(0.015)$ \\
& $-0.045^{* *}$ & 0.004 \\
Share Irrigated & {$[0.134]$} & {$[0.128]$} \\
& $(0.015)$ & $(0.010)$ \\
Trend & -0.002 & $-0.008^{* *}$ \\
& {$[0.005]$} & {$[0.005]$} \\
Intercept & $(0.001)$ & $(0.001)$ \\
& 0.251 & 0.310 \\
& {$[2.899]$} & {$[2.542]$} \\
& $(0.268)$ & $(0.395)$ \\
& $0.013^{* *}$ & 0.005 \\
Obser & {$[0.014]$} & {$[0.012]$} \\
& $(0.004)$ & $(0.003)$ \\
& $0.372^{* *}$ & $0.669^{* *}$ \\
& {$[0.118]$} & {$[0.127]$} \\
& $(0.027)$ & $(0.018)$ \\
& 3.151936 & 2.635 .60
\end{tabular}

Observations $\quad 3,151,936 \quad 2,635,969$

Notes: This table gives average coefficients of the Markov transition models across MLRAs. The standard deviation of coefficients across MLRAs is in brackets. The average and standard deviation are weighted by the acres in each MLRA. The standard error of the average coefficient is in parentheses. Standard errors are clustered by year and estimated with a wild bootstrap.

** Significant at the 5 percent level.

*Significant at the 10 percent level. 
Table 4: Corn Acreage Elasticities at the Rotational Margin with Pooled Estimators and Field-level Data

\begin{tabular}{ccccc}
\hline \hline & & \multicolumn{3}{c}{ Lagged Dependent Variable } \\
\cline { 3 - 5 } & Transition Probabilities & OLS & FE & Arellano-Bond \\
& $(1)$ & $(2)$ & $(3)$ & $(4)$ \\
\hline Own-Price & & & & \\
Short-run & 0.25 & 0.22 & $0.33^{* *}$ & 0.32 \\
Long-run & $(0.158)$ & $(0.161)$ & $(0.131)$ & $(1.403)$ \\
& 0.16 & 0.14 & $0.20^{* *}$ & 0.18 \\
Cross-Price & $(0.102)$ & $(0.104)$ & $(0.078)$ & $(0.822)$ \\
Short-run & & & & \\
Long-run & -0.15 & -0.12 & -0.17 & -0.18 \\
& $(0.182)$ & $(0.186)$ & $(0.143)$ & $(1.107)$ \\
& -0.09 & -0.08 & -0.10 & -0.11 \\
$\frac{\varepsilon_{L R}-\varepsilon_{S R}}{\varepsilon_{L R}}$ & $(0.117)$ & $(0.121)$ & $(0.085)$ & $(0.648)$ \\
& $-0.56^{* *}$ & $-0.54^{* *}$ & $-0.68^{* *}$ & $-0.71^{* *}$ \\
& $(0.014)$ & $(0.009)$ & $(0.007)$ & $(0.012)$ \\
\hline
\end{tabular}

Notes: This table reports results at the rotational margin for models that estimate a single coefficient for all fields (i.e., pooled estimators). Results in column (1) are from linear Markov transition probability models as in equations (14) and (15), but impose the same coefficients across all fields. Results in columns (2)-(4) are from a linear probability model with a single lagged dependent variable as in equation (22), but impose the same coefficients across all fields. Results in columns (2) and (3) are from Ordinary Least Squares (OLS) and fixed effects (FE). The Arellano-Bond estimates in (4) are estimated with two-step difference GMM using XTABOND2 in STATA using a "collapsed" instrument matrix as suggested by Roodman (2009), and use all lags available as instruments. Standard errors are clustered by year.

** Significant at the 5 percent level.

${ }^{*}$ Significant at the 10 percent level. 
Table 5: Aggregate Corn Acreage Elasticities with Alternative Estimators using Aggregate Panel Data and a Single Lagged Dependent Variable

\begin{tabular}{|c|c|c|c|c|c|c|}
\hline & \multicolumn{5}{|c|}{ County-level } & \multirow{2}{*}{$\begin{array}{c}\text { Random Groups } \\
\text { OLS } \\
(6)\end{array}$} \\
\hline & $\begin{array}{l}\mathrm{FE} \\
(1)\end{array}$ & $\begin{array}{c}\text { Anderson- } \\
\text { Hsiao } \\
(2)\end{array}$ & $\begin{array}{c}\text { Arellano- } \\
\text { Bond } \\
(3)\end{array}$ & $\begin{array}{c}\text { Arellano- } \\
\text { Bond } \\
(4)\end{array}$ & $\begin{array}{l}\text { Blundell- } \\
\text { Bond } \\
(5)\end{array}$ & \\
\hline \multicolumn{7}{|l|}{ Own-Price } \\
\hline Short-run & $\begin{array}{c}0.35^{* *} \\
(0.131)\end{array}$ & $\begin{array}{l}0.50^{* *} \\
(0.160)\end{array}$ & $\begin{array}{c}0.44 \\
(0.314)\end{array}$ & $\begin{array}{c}0.14 \\
(0.750)\end{array}$ & $\begin{array}{c}0.41 \\
(0.517)\end{array}$ & $\begin{array}{l}0.36^{* *} \\
(0.149)\end{array}$ \\
\hline Long-run & $\begin{array}{c}0.44^{* *} \\
(0.187)\end{array}$ & $\begin{array}{c}0.62 \\
(0.556)\end{array}$ & $\begin{array}{c}0.55 \\
(0.409)\end{array}$ & $\begin{array}{c}0.11 \\
(0.672)\end{array}$ & $\begin{array}{c}0.41 \\
(0.600)\end{array}$ & $\begin{array}{c}0.23^{*} \\
(0.114)\end{array}$ \\
\hline \multicolumn{7}{|l|}{ Cross-Price } \\
\hline Short-run & $\begin{array}{l}-0.38^{* *} \\
(0.140)\end{array}$ & $\begin{array}{l}-0.49^{* *} \\
(0.191)\end{array}$ & $\begin{array}{l}-0.45^{* *} \\
(0.230)\end{array}$ & $\begin{array}{c}-0.12 \\
(0.818)\end{array}$ & $\begin{array}{c}-0.36 \\
(0.446)\end{array}$ & $\begin{array}{c}-0.24 \\
(0.186)\end{array}$ \\
\hline Long-run & $\begin{array}{l}-0.47^{* *} \\
(0.209)\end{array}$ & $\begin{array}{c}-0.62 \\
(0.642)\end{array}$ & $\begin{array}{c}-0.56 \\
(0.356)\end{array}$ & $\begin{array}{c}-0.09 \\
(0.724)\end{array}$ & $\begin{array}{c}-0.36 \\
(0.530)\end{array}$ & $\begin{array}{c}-0.15 \\
(0.139)\end{array}$ \\
\hline$\frac{\varepsilon_{L R}-\varepsilon_{S R}}{\varepsilon_{L R}}$ & $\begin{array}{c}0.19^{*} \\
(0.101)\end{array}$ & $\begin{array}{c}0.21 \\
(0.555)\end{array}$ & $\begin{array}{c}0.20 \\
(0.307)\end{array}$ & $\begin{array}{c}-0.29 \\
(1.375)\end{array}$ & $\begin{array}{c}0.01 \\
(0.462)\end{array}$ & $\begin{array}{c}-0.55 \\
(0.311)\end{array}$ \\
\hline $\begin{array}{l}\text { Maximum number } \\
\text { of lags as instruments }\end{array}$ & $\mathrm{N} / \mathrm{A}$ & 1 & 5 & 10 & 10 & $\mathrm{~N} / \mathrm{A}$ \\
\hline
\end{tabular}

Notes: The county-level results in this table use official NASS county-level data. The dependent variable is corn acres divided the average sum of corn and soybean acres during the sample for the county (i.e., the share of corn and soybean acres planted to corn). Right-hand side variables are a lagged dependent variable, expected corn price, expected soybean price, a trend, and county-specific intercepts. The results in column (2) are from the Anderson-Hsiao estimator that uses the second lagged level as an instrument for the lagged difference. The results in (3) and (4) are two-step difference GMM and estimates in (5) are two-step system GMM, estimated using XTABOND2 in STATA using a collapsed instrument matrix as suggested by Roodman (2009). Results in (3) use a maximum of 5 lags as instruments and results in (4) and (5) use all lags available as instruments. Results in (7) are from pooled OLS when the field-level data are randomly assigned to 100 different groups and aggregated within those groups. Standard errors for all estimators are clustered by year.

${ }^{* *}$ Significant at the 5 percent level.

${ }^{*}$ Significant at the 10 percent level. 